\title{
Back to the Future: Rethinking the Great Potential of IncRNAs for Optimizing Chemotherapeutic Response in Ovarian Cancer
}

\author{
Abdelrahman M. Elsayed ${ }^{1,2}$, Paola Amero ${ }^{1}\left(\right.$, Salama A. Salama ${ }^{2}{ }^{\oplus}$, Abdelaziz H. Abdelaziz ${ }^{2}$, \\ Gabriel Lopez-Berestein ${ }^{1,3}$ and Cristian Rodriguez-Aguayo ${ }^{1,3, * \text { (D) }}$ \\ 1 Department of Experimental Therapeutics, The University of Texas MD Anderson Cancer Center, \\ Houston, TX 77030, USA; AMHamoda@mdanderson.org (A.M.E.); PAmero@mdanderson.org (P.A.); \\ glopez@mdanderson.org (G.L.-B.) \\ 2 Department of Pharmacology and Toxicology, Faculty of Pharmacy, Al-Azhar University, Cairo 11675, Egypt; \\ salama@azhar.edu.eg (S.A.S.); abdelazizhamed@azhar.edu.eg (A.H.A.) \\ 3 Department of Cancer Biology, Center for RNA Interference and Non-Coding RNA, The University of Texas \\ MD Anderson Cancer Center, Houston, TX 77030, USA \\ * Correspondence: CRodriguez2@mdanderson.org; Tel.: +1-713-563-6150
}

Received: 24 June 2020; Accepted: 20 August 2020; Published: 25 August 2020

\begin{abstract}
Ovarian cancer (OC) is one of the most fatal cancers in women worldwide. Currently, platinum- and taxane-based chemotherapy is the mainstay for the treatment of OC. Yet, the emergence of chemoresistance results in therapeutic failure and significant relapse despite a consistent rate of primary response. Emerging evidence substantiates the potential role of lncRNAs in determining the response to standard chemotherapy in OC. The objective of this narrative review is to provide an integrated, synthesized overview of the current state of knowledge regarding the role of lncRNAs in the emergence of resistance to platinum- and taxane-based chemotherapy in OC. In addition, we sought to develop conceptual frameworks for harnessing the therapeutic potential of lncRNAs in strategies aimed at enhancing the chemotherapy response of OC. Furthermore, we offered significant new perspectives and insights on the interplay between lncRNAs and the molecular circuitries implicated in chemoresistance to determine their impacts on therapeutic response. Although this review summarizes robust data concerning the involvement of lncRNAs in the emergence of acquired resistance to platinum- and taxane-based chemotherapy in OC, effective approaches for translating these lncRNAs into clinical practice warrant further investigation.
\end{abstract}

Keywords: long non-coding RNAs; mechanisms of resistance; chemotherapy; dysregulated expression; ovarian cancer

\section{Introduction}

Ovarian cancer (OC) is the most lethal gynecological malignancy in women, accounting for approximately 150,000 annual deaths worldwide. For patients with advanced stages of OC, overall survival averages only 5 years due to the disease's asymptomatic nature during the early stages, leading to late diagnosis and resistance to conventional chemotherapy. Although most patients initially respond to chemotherapy, the majority of them relapse and develop resistance to chemotherapy [1]. Based on its genetic behavior and histological features, OC can be classified into two major types [2]. Type I includes mucinous, clear cell, endometrioid, and low-grade serous carcinomas, and mutations of PTEN, BRAF, KRAS, and CTNNB1 have been identified [3]. Type II accounts for approximately $90 \%$ of OC cases and comprises high-grade serous cancers, carcinosarcomas, and undifferentiated carcinomas. Remarkably, type II tumors include more aggressive epithelial malignancies that have a 
higher tendency for invasion and metastasis. These tumors are associated with multiple mutations of TP53 and BRCA1/2 genes [4]. Notably, high-grade serous carcinoma is the most common, with the highest mortality rate [5].

Currently, the standard treatment approach for newly diagnosed OC patients includes surgical removal of the tumor followed by chemotherapy with a platinum-based antineoplastic (either cisplatin or carboplatin) combined with a taxane (either paclitaxel (PTX) or docetaxel) [6]. An alternative strategy comprises neoadjuvant chemotherapy followed by tumor debulking and subsequent chemotherapy. Tumor recurrence as a result of the emergence of platinum resistance is the most difficult issue for the management of OC [5]. Advances in OC management include the use of angiogenesis inhibitors such as bevacizumab, poly (ADP-ribose) polymerase (PARP) inhibitors, and immunotherapy-based agents. However, due to the development of chemoresistance, the outcomes of these new treatment modalities have been dismal as there was no significant increase in overall survival [5].

It was previously thought that most of the human genome, up to $75 \%$, is transcribed into non-coding RNAs (ncRNAs), whereas less than $2 \%$ of the human genome encodes protein. However, recent data shed light on the numerous and indispensable functions of ncRNAs, particularly in carcinogenesis and chemoresistance [7-9]. Long non-coding RNAs (lncRNAs) are defined as RNA transcripts comprising more than 200 nucleotides, and most of them are incapable of encoding proteins [10]. Nevertheless, recent evidence has proven that lncRNAs can encode for peptides/proteins, which usually contain less than 100 amino acids [11,12]. According to the data obtained from the Encyclopedia of DNA Elements (ENCODE) project, more than 28,000 lncRNA transcripts are generated by approximately 16,000 genes and represent the most diverse class of ncRNAs [13]. In the context of cancer, mounting evidence indicates that aberrant expression of lncRNAs is associated with the development of multiple malignancies [14]. In OC, certain lncRNAs function as oncogenes, while others might function as tumor suppressors and therefore modulate tumor growth and response to chemotherapy [15]. Indeed, certain lncRNAs can be targeted as a potential therapeutic approach to ameliorate chemoresistance [15]. Thus, in this review, we summarize the potential mechanisms of lncRNAs underlying resistance to platinums and taxanes in OC.

\section{Classification of lncRNAs}

lncRNAs are broadly classified based on genomic origin into intergenic, intronic, bidirectional, sense, and antisense lncRNAs. Intergenic lncRNA originates from a genomic sequence located between two subsequent protein-coding genes [16]. Intronic lncRNA develops when the entire sequence of lncRNA is located within the intron of a protein-coding gene [17]. Bidirectional lncRNA exists within $1 \mathrm{~kb}$ of the protein-coding gene promoter, but is transcribed from the opposite DNA strand [18]. Sense and antisense lncRNAs develop if located between one or more exons of another transcript on the same or opposite strand, respectively (Figure 1) [19,20]. 


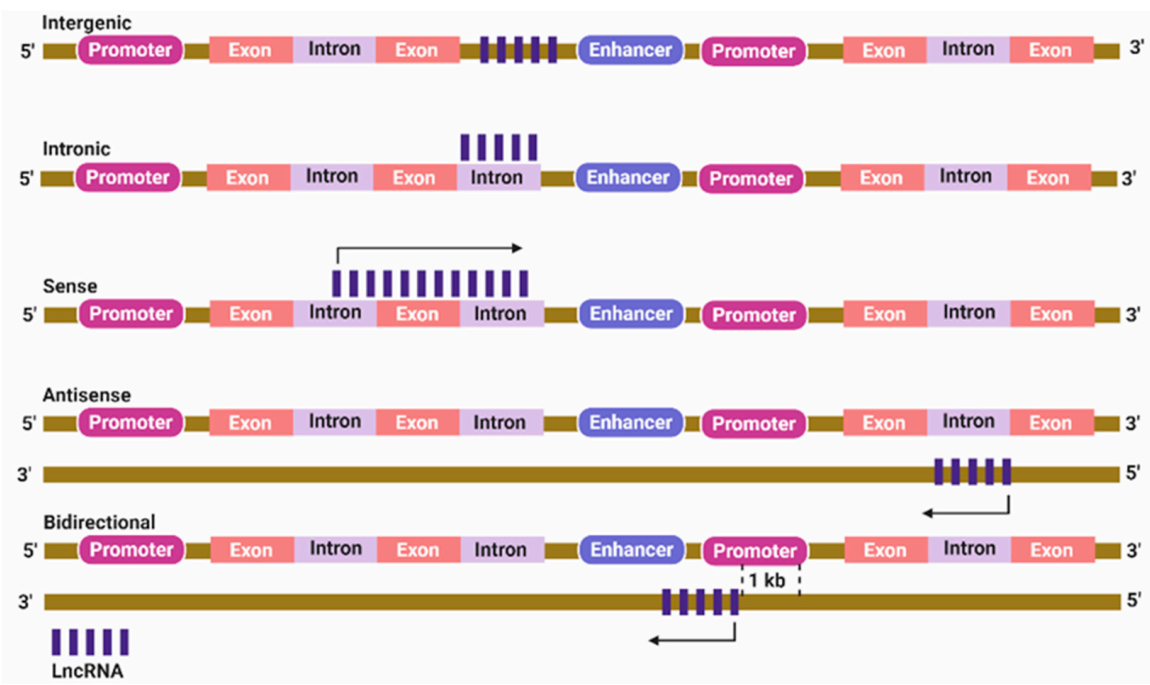

Figure 1. Classification of long non-coding RNAs (lncRNAs) based on their genomic location. Intergenic lncRNA is located between two protein-coding genes. Intronic lncRNA lies entirely within the intron of a protein-coding gene. Sense lncRNA is transcribed from the same strand and in the same direction as the nearby protein-coding genes. Antisense lncRNA is transcribed from an opposite strand. Bidirectional lncRNA is located within $1 \mathrm{~kb}$ of the promoter region of a protein-coding gene but is transcribed from an opposite strand.

\section{Localization of lncRNAs}

It is well known that mRNA is first biosynthesized in the nucleus as a pre-mRNA then exported into the cytoplasm, where it can easily be recognized by ribosomal and transfer RNAs, eventually leading to protein translation. Unlike mRNA, the functions of lncRNAs rely mainly on physical interactions with either RNAs or proteins, and these interactions in turn depend on close vicinity; therefore, IncRNAs can find their way to particular locations inside or outside the nucleus [21]. Although the prevailing narratives reported that the nucleus harbors most lncRNAs where they can regulate gene expression mainly via epigenetic regulation, subsequent studies have identified many lncRNAs with cytoplasmic localization [22,23]. For instance, Bouvrette et al. demonstrated that approximately $75 \%$ of lncRNAs are found in cytoplasmic fractions of human and Drosophila cells [24]. Similarly, a higher proportion of lncRNAs (about $40 \%$ ) has been identified in the cytoplasm compared with approximately $4 \%$ nuclear fraction in a study conducted via using RNA fluorescence in situ hybridization (FISH) and Drosophila models [25]. IncRNAs have a complex distribution in a wide variety of cellular compartments and organelles. Within the cytoplasm, lncRNAs can present in mitochondria [26], ribosomes [27], extracellular membranes [28], exosomes [29], and other components. In the nucleus, lncRNAs have been identified in chromatin speckles (nuclear domains enriched in splicing factors), paraspeckles (ribonucleoprotein domains located at interchromatin spaces and involved in nuclear retention of mRNA), and nucleoli (the largest body in the nucleus, where the ribosomal biosynthesis occurs) $[23,30,31]$. In conclusion, identifying lncRNAs' subcellular localization may pave the path for determining their subsequent biological functions [23].

\section{Major Biological Functions of lncRNAs}

Although lncRNAs exert innumerable biological functions, their action can be generally categorized into four main archetypes of molecular mechanisms: signals, guides, decoys, and scaffolds. Remarkably, the function of lncRNAs is multifactorial in that a single lncRNA can fulfill multiple archetypes [32]. Given that lncRNA expression patterns are cell and tissue specific and that diverse stimuli can induce lncRNA expression, some lncRNAs can serve as molecular signals in response to particular stimuli, and these lncRNAs can be utilized as biomarkers in different biological events [32]. In addition, 
lncRNAs can also function as guide molecules, in which lncRNAs bind to particular regulatory proteins or enzymes like transcription factors or chromatin-modifying complexes and precisely direct them to the exact locations within the genome to regulate gene expression [33]. For instance, the homeobox transcript antisense RNA (HOTAIR), located at the HOXC locus, guides polycomb repressive complex 2 (PRC2) to the HOXD locus to regulate gene expression. Importantly, aberrant expression of HOTAIR is associated with the development of several types of cancer [34]. In contrast to the guide function, some lncRNAs can serve as decoys by binding to and sequestering miRNAs, RNA-binding proteins, catalytic proteins, modifying complexes, and transcription factors to negatively regulate their function [35]. In the case of miRNAs, certain IncRNAs regulate gene expression by sequestering miRNAs and circumventing the subsequent interaction with the target mRNAs and therefore inhibiting miRNA-induced gene silencing [36]. This mode of action is called "miRNA sponging," and the lncRNAs that act by this mechanism are called competitive endogenous RNAs (ceRNAs) [37]. The fourth and the most intricate molecular archetype is the scaffold function. In this archetype, lncRNAs function as docking sites upon which distinct effector proteins interact at the same time, thereby bringing the effector molecules together at the same time and place. This scaffolding process enables the transmission of signals and therefore the regulation of multiple biological processes [32]. In addition, IncRNAs exert diverse regulatory functions that originate from these archetypes. For instance, lncRNAs regulate gene expression by regulating (1) chromatin remodeling; (2) transcription and post-transcription modifications, e.g., alternative splicing; (3) translation and post-translation modifications, e.g., ubiquitination and phosphorylation; and (4) mRNA and protein stability [35]. Finally, although originally identified as non-protein coding, recent studies have shown that some lncRNAs encode micropeptides with definitive biological functions (Figure 2) [38].
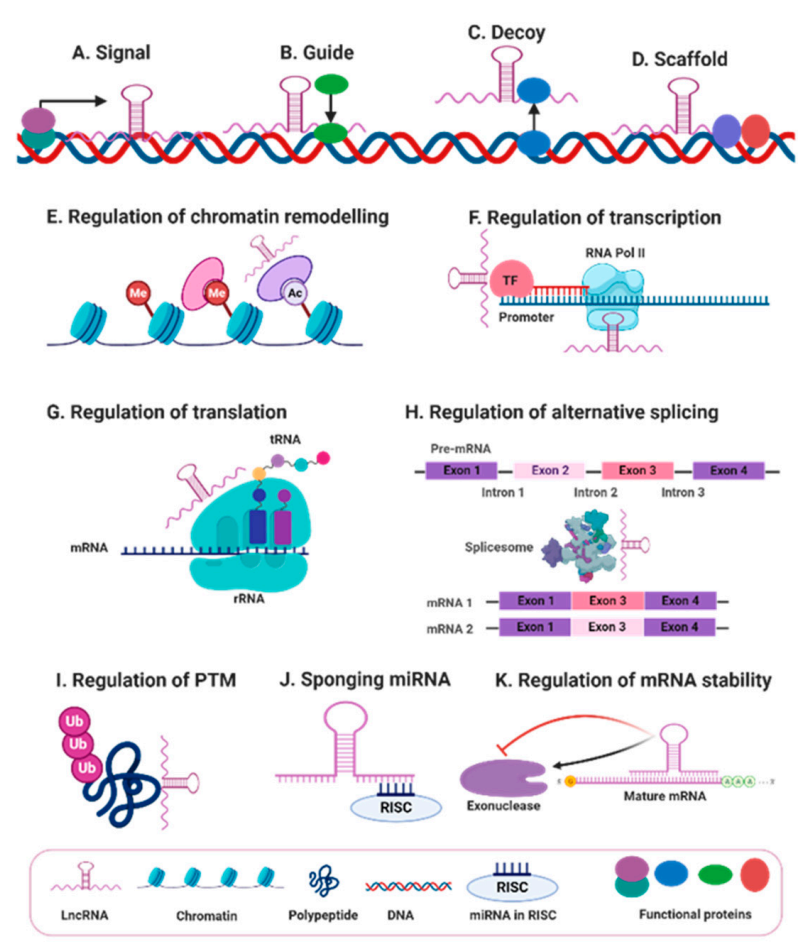

Figure 2. General biological functions of lncRNAs. IncRNA biological functions are generally categorized into four main archetypes of molecular mechanisms, including (A) signals, (B) guides, (C) decoys, and (D) scaffolds. In addition, lncRNAs exert diverse regulatory functions originating from these archetypes such as regulation of; (E) chromatin remodeling via modulating recruitment of epigenetic factors, (F) transcription through controlling transcription factors or RNA polymerase 2 (RNA pol II), (G) protein translation, (H) alternative splicing and other post-transcriptional modifications, (I) protein ubiquitination and other post-translational modifications (PTMs), (J) miRNA-induced gene silencing via sponging miRNA as a part of the RNA-induced silencing complex (RISC), and (K) mRNA stability by modulating mRNA-degrading enzymes. 


\section{IncRNAs and Chemoresistance in Ovarian Cancer}

The therapeutic approach for advanced OC relies on maximum tumor debulking followed by platinum- and taxane-based chemotherapy. Despite advances in therapeutic modalities, intrinsic or acquired resistance to platinum and/or taxane therapy remains the major reason for poor survival rates in OC patients, even when the initial response is promising [6]. Thus, understanding the molecular mechanisms implicated in chemoresistance is indispensable to improve the overall clinical outcomes of OC patients. A growing body of evidence suggests that aberrant expression of lncRNAs is associated with the development of multiple malignancies and chemoresistance [14]. Differential expression of lncRNAs has been identified in cisplatin-resistant and cisplatin-sensitive OC, advocating their predicted role in the emergence of chemoresistance. However, precisely how lncRNAs contribute to chemoresistance remains undefined. Here, we provide an updated insight into the molecular mechanisms by which lncRNAs induce pharmacological resistance and how they represent potential targets in the development of effective therapy and biomarkers in OC.

\subsection{IncRNAs and Platinum Resistance}

Since its approval by the US Food and Drug Administration in 1987, cisplatin and other platinum-based compounds have become the foundation for the management of a wide array of solid malignancies including ovarian, testicular, head and neck, lung, bladder, esophageal, and colon cancers. Currently, three platinum-based agents are used clinically: cisplatin, carboplatin, and oxaliplatin. Among those, only cisplatin and carboplatin are approved for the first-line treatment of advanced-stage OC [39]. Mechanistically, platinum analogues exert their action mainly through binding to the N7 position of guanine nucleotides, leading to the formation of DNA adducts, intrastrand and interstrand cross-links. The resultant single- and double-strand breaks impact DNA repair machinery, thereby inducing cell cycle arrest and apoptosis. In addition, platinum analogues enhance the release of reactive oxygen species (ROS), which in turn contribute to platinum-induced cytotoxicity [40]. Despite successful initial responses, many OC patients acquire chemoresistance to cisplatin and/or carboplatin, resulting in overall therapeutic failure [40]. Therefore, there is an urgent need to uncover the molecular pathways implicated in platinum resistance to improve therapeutic outcomes.

The mechanistic circuitries encountered in platinum resistance are multifactorial and include reduced intracellular drug uptake, enhanced drug efflux via multi-drug resistant transporters, and increased intracellular sequestration by nucleophilic scavengers such as reduced glutathione (GSH) and metallothioneins. Likewise, the activation of DNA repair systems, evasion of apoptosis, alteration of autophagy, increased cancer stemness, and activation of survival pathways such as the PI3K/AKT axis play a fundamental role in conferring resistance to platinum-based chemotherapy $[9,41]$. The activation of DNA repair systems such as the nucleotide excision repair and homologous recombination (HR) can retard the apoptotic process, ultimately leading to platinum resistance. Importantly, the downregulation of breast cancer susceptibility proteins 1 and 2 (BRCA1/2), the two critical factors in the homologous recombination system, enhances platinum sensitivity in multiple cancers [42]. The activation of the mismatch repair (MMR) system also enhances platinum sensitivity because it can recognize platinum-induced DNA lesion and consequently activate apoptosis. Importantly, the downregulation of MMR-related genes such as MLH1 and MSH2 is implicated in the emergence of platinum resistance [43]. Furthermore, dysregulation of tumor suppressor protein p 53 and its related nuclear transcription factors play a fundamental role in platinum resistance [44,45]. Accumulating evidence indicates that several lncRNAs are associated with the emergence of cisplatin or carboplatin resistance. In Table 1, we present and categorize these lncRNAs based on the mechanisms implicated in platinum chemoresistance. 
Table 1. List of lncRNAs associated with platinum resistance.

\begin{tabular}{|c|c|c|c|c|c|}
\hline Name of lncRNA & Classification & Type of Cancer & Role in Platinum Resistance & Mechanism & Reference \\
\hline ZFAS1 (Zinc finger antisense 1) & Antisense & Ovarian cancer & $\uparrow$ Cisplatin resistance & $\begin{array}{l}\text { Regulating CTR1 expression via regulating } \\
\text { miR-150-5p/SP1 axis }\end{array}$ & [46] \\
\hline $\begin{array}{l}\text { MALAT1 (metastasis-associated } \\
\text { lung adenocarcinoma transcript 1) }\end{array}$ & Intergenic & Ovarian cancer & $\uparrow$ Cisplatin resistance & Regulating Notch1/ABCC1/MRP1 signaling pathway & [47] \\
\hline $\begin{array}{l}\text { GAS5 (growth arrest-specific } \\
\text { transcript 5) }\end{array}$ & Antisense & Ovarian cancer & $\downarrow$ Cisplatin resistance & $\begin{array}{c}\downarrow \text { PARP1 and } \downarrow \text { phosphorylation of ERK, JNK, } \\
\text { and MAPK }\end{array}$ & [48] \\
\hline $\begin{array}{l}\text { NEAT1 (nuclear-enriched abundant } \\
\text { transcript 1) }\end{array}$ & Intergenic & Lung cancer & $\downarrow$ Cisplatin resistance & Upregulating EGCG-induced CTR1 expression & [49] \\
\hline $\begin{array}{l}\text { H19 (imprinted maternally } \\
\text { expressed transcript) }\end{array}$ & Intergenic & Ovarian cancer & $\uparrow$ Cisplatin resistance & $\begin{array}{l}\uparrow \text { Expression of NRF2-targeted proteins and } \uparrow \text { GSH } \\
\text { activity } \rightarrow \downarrow \text { cisplatin-induced oxidative cytotoxicity }\end{array}$ & [50] \\
\hline H19 & Intergenic & Ovarian cancer & $\uparrow$ Cisplatin resistance & 个 TWIST, SLUG, and SNAIL $\rightarrow \uparrow$ EMT & [51] \\
\hline \multirow{6}{*}{$\begin{array}{l}\text { HOTAIR (HOX transcript } \\
\text { antisense RNA) }\end{array}$} & \multirow{6}{*}{ Antisense } & Ovarian cancer & $\uparrow$ Cisplatin resistance & Activating ATG7 and enhancing autophagy & [52] \\
\hline & & Endometrial cancer & $\uparrow$ Cisplatin resistance & Activating beclin-1 and enhancing autophagy & [53] \\
\hline & & Ovarian cancer & $\uparrow$ Cisplatin resistance & Regulating miR-138-5p/EZH2/SIRT1 axis & [54] \\
\hline & & Ovarian cancer & $\uparrow$ Cisplatin resistance & Activating Wnt $/ \beta$-catenin pathway $\rightarrow \uparrow$ EMT & [55] \\
\hline & & Ovarian cancer & $\uparrow$ Cisplatin resistance & $\begin{array}{l}\text { HOTAIR } \uparrow \text { NF-kB, IL-6, and CHK1-p53-p21 } \rightarrow \text { repair of } \\
\text { damaged DNA }\end{array}$ & [56] \\
\hline & & Ovarian cancer & $\uparrow$ Carboplatin resistance & Unknown & [57] \\
\hline $\begin{array}{l}\text { PANDAR (promoter of CDKN1A } \\
\text { antisense DNA damage } \\
\text { activated RNA) }\end{array}$ & Antisense & Ovarian cancer & $\uparrow$ Cisplatin resistance & $\begin{array}{c}\text { Modulating PANDAR/SRFS2/p53 axis } \rightarrow \downarrow \\
\text { p53-induced apoptosis }\end{array}$ & [58] \\
\hline $\begin{array}{l}\text { EPEL (E2F-mediated proliferation } \\
\text { enhancing lncRNA) }\end{array}$ & Intergenic & Endometroid cancer & $\uparrow$ Carboplatin resistance & $\downarrow$ Expression of p53 $\rightarrow \downarrow$ apoptosis. & [59] \\
\hline $\begin{array}{l}\text { PVT1 (plasmacytoma variant } \\
\text { translocation 1) }\end{array}$ & Intergenic & Ovarian cancer & $\begin{array}{l}\downarrow \text { Carboplatin and docetaxel } \\
\text { resistance }\end{array}$ & $\begin{array}{c}\uparrow \text { p53 and TIMP1 } \rightarrow \uparrow \text { apoptosis and } \downarrow \text { tumor } \\
\text { invasion, respectively. }\end{array}$ & {$[60]$} \\
\hline $\begin{array}{l}\text { CCAT1 (colon cancer-associated } \\
\text { transcript } 1 \text { ) }\end{array}$ & Antisense & Ovarian cancer & $\uparrow$ Cisplatin resistance & Modulating miR-454/survivin pathway & {$[61]$} \\
\hline $\begin{array}{l}\text { LINC00152 (long intergenic } \\
\text { non-coding RNA 152) }\end{array}$ & Intergenic & Ovarian cancer & $\uparrow$ Cisplatin resistance & $\uparrow$ MDR1 and MRP1 and $\downarrow$ apoptosis & [62] \\
\hline $\begin{array}{l}\text { UCA1 (urothelial carcinoma } \\
\text { associated 1) }\end{array}$ & Intergenic & Ovarian cancer & $\uparrow$ Cisplatin resistance & Regulating miR-143/FOSL2 axis & [63] \\
\hline $\begin{array}{l}\text { SNHG22 (small nucleolar RNA } \\
\text { host gene 22) }\end{array}$ & Antisense & Ovarian cancer & $\begin{array}{c}\uparrow \text { Cisplatin and } \\
\text { paclitaxel resistance }\end{array}$ & Regulating miR-2467/Gal-1 signaling cascade & [64] \\
\hline LINC01125 & Sense-overlapping & Ovarian cancer & $\begin{array}{c}\downarrow \text { Cisplatin and } \\
\text { paclitaxel resistance }\end{array}$ & Regulating miR-1972/apoptosis pathway & [65] \\
\hline
\end{tabular}


Table 1. Cont.

\begin{tabular}{|c|c|c|c|c|c|}
\hline Name of lncRNA & Classification & Type of Cancer & Role in Platinum Resistance & Mechanism & Reference \\
\hline ENST00000457645 & Intergenic & Ovarian cancer & $\downarrow$ Cisplatin resistance & Unknown & [66] \\
\hline BCYRN1 (brain cytoplasmic RNA1) & Intergenic & Ovarian cancer & $\downarrow$ Carboplatin resistance & Unknown & [67] \\
\hline CASC11 (cancer susceptibility 11) & Intergenic & Ovarian cancer & $\begin{array}{c}\uparrow \text { Cisplatin and } \\
\text { carboplatin resistance }\end{array}$ & Unknown & [68] \\
\hline $\begin{array}{c}\text { SNHG15 (small nucleolar RNA } \\
\text { host gene 15) }\end{array}$ & Intergenic & Ovarian cancer & $\uparrow$ Cisplatin resistance & Unknown & [69] \\
\hline $\begin{array}{l}\text { CRNDE (colorectal neoplasia } \\
\text { differentially expressed) }\end{array}$ & Intergenic & Ovarian cancer & $\begin{array}{c}\text { Upregulated in } \\
\text { cisplatin resistance }\end{array}$ & Unknown & [70] \\
\hline RP11-1A16.1 & Intergenic & Ovarian cancer & $\begin{array}{l}\text { Downregulated in } \\
\text { cisplatin resistance }\end{array}$ & Unknown & [70] \\
\hline AC000035.3 & Intergenic & Ovarian cancer & $\begin{array}{l}\text { Downregulated in } \\
\text { cisplatin resistance }\end{array}$ & Unknown & [70] \\
\hline AC003986.7 & Antisense & Ovarian cancer & $\begin{array}{c}\text { Upregulated in } \\
\text { cisplatin resistance }\end{array}$ & Unknown & [70] \\
\hline RP11-6N17.4 & Bidirectional & Ovarian cancer & $\begin{array}{c}\text { Upregulated in } \\
\text { cisplatin resistance }\end{array}$ & Unknown & [70] \\
\hline PLAC2 & Intronic & Ovarian cancer & $\begin{array}{c}\text { Upregulated in } \\
\text { cisplatin resistance }\end{array}$ & Unknown & [70] \\
\hline CTD-2026G22.1 & Intergenic & Ovarian cancer & $\begin{array}{l}\text { Downregulated in } \\
\text { cisplatin resistance }\end{array}$ & Unknown & [70] \\
\hline RP11-1A16.1 & Intergenic & Ovarian cancer & $\begin{array}{l}\text { Downregulated in } \\
\text { cisplatin resistance }\end{array}$ & Unknown & {$[70]$} \\
\hline
\end{tabular}

The arrows in this table refer to: $\uparrow$ (increase); $\downarrow$ (decrease); $\rightarrow$ (leading to). 


\subsubsection{Reduced Intracellular Accumulation}

One of the major mechanisms encountered in platinum resistance is reduced intracellular drug accumulation as a result of either reduced uptake or enhanced efflux of the drug. Thus, the regulation of protein transporters that mediate cisplatin uptake and efflux plays a fundamental role in platinum resistance. Of those transporters, copper transporter 1 (CTR1), a transmembrane protein that regulates copper homeostasis, plays a significant role in cisplatin uptake across the cell membrane [40]. Interestingly, the downregulation of CTR1 significantly blocked cisplatin uptake in yeast and in mouse embryonic fibroblasts [71,72]. Zinc finger antisense 1 (ZFAS1) is an lncRNA transcribed from the antisense strand in close proximity to the protein-coding gene ZNFX1 [73]. In cancer, ZFAS1 has a tissue-specific function as evidenced by its different expression patterns among various human malignancies [9]. In OC, ZFAS1 was associated with cisplatin resistance, and silencing ZFAS1 improved cisplatin sensitivity, at least in part, by regulating the miR-150-5p/specific protein 1 (SP1) axis [46]. SP1 is a transcriptional factor that regulates CTR1 [74] and DNA damage response (DDR) [75]. Thus, ZFAS1 could induce cisplatin resistance through modulating SP1-mediated CTR1 expression. More studies need to be conducted to reveal the exact relationship between lncRNAs and CTR1 in OC. In lung cancer, nuclear-enriched abundant transcript 1 (NEAT1) has been shown to enhance cisplatin sensitivity via upregulating epigallocatechin-3-gallate (EGCG)-induced CTR1 expression [49].

Previous reports have demonstrated the role of ATP-binding cassette (ABC) transporters, particularly P-glycoprotein and multi-drug resistant proteins (MRPs), in platinum resistance via triggering the efflux process [41]. Metastasis-associated lung adenocarcinoma transcript 1 (MALAT-1), the first identified cancer-associated lncRNA, is upregulated in malignancies such as ovarian, lung, colon, cervical, and prostate cancer and employed as a prognostic factor for metastasis and survival [76,77]. Bai et al. elucidated that MALAT1 is overexpressed in OC and is positively correlated with cisplatin resistance and Notch1 in OC tissues and cisplatin-resistant cells [47]. Mechanistically, silencing MALAT1 significantly inhibited Notch1 and $\mathrm{ABCC} 1$ and enhanced cisplatin chemosensitivity. Moreover, Notch1 knockdown reversed cisplatin resistance and reduced the expression of $A B C C 1 / M R P 1$ in cisplatin-resistant cells. Based on these data, the authors speculated that MALAT1 enhances cisplatin resistance through regulating the Notch1/ABCC1/MRP1 signaling pathway, and therefore MALAT 1 could be used as a promising therapeutic approach to enhance cisplatin sensitivity in OC (Figure 3) [47]. 


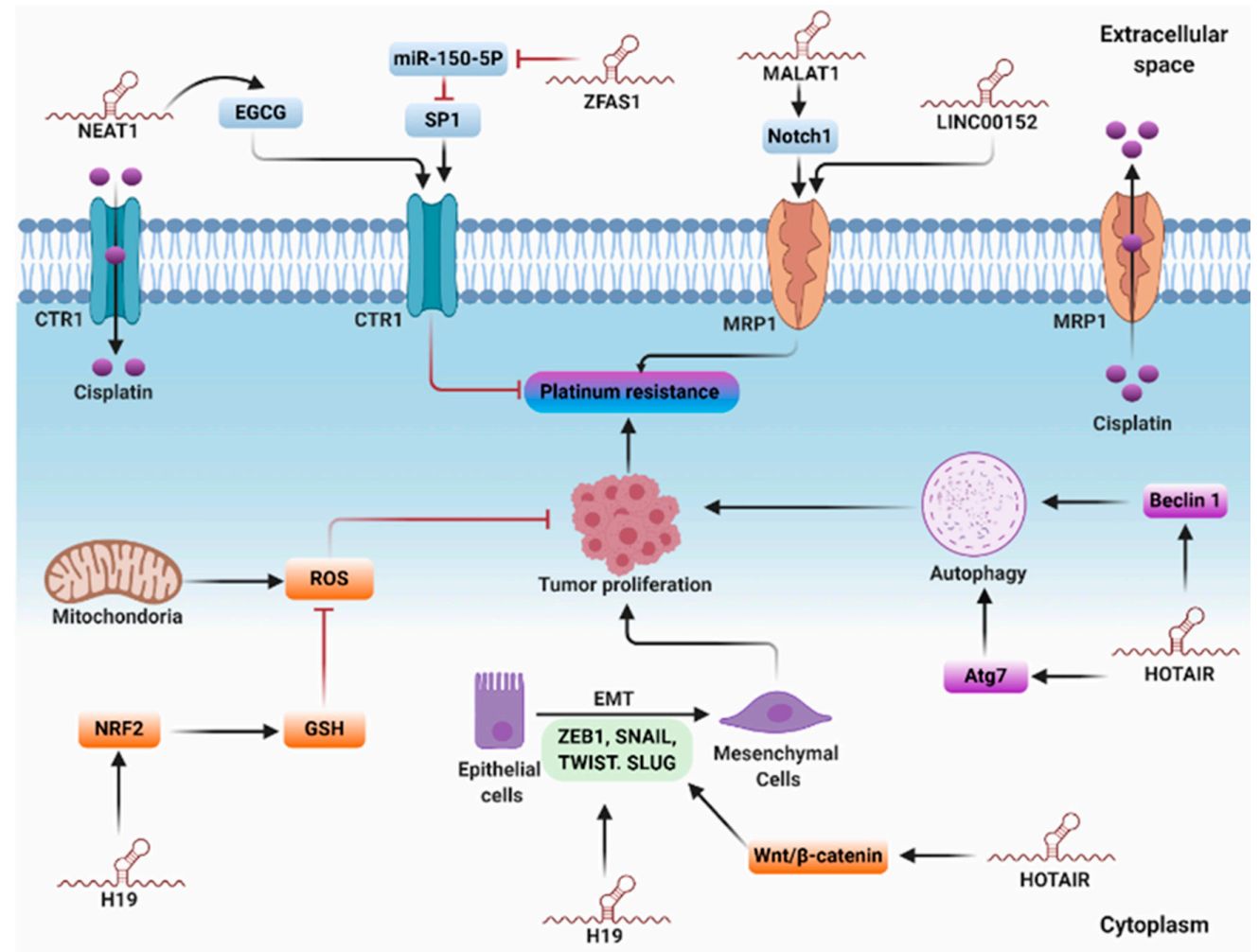

Figure 3. Molecular mechanisms of lncRNAs involved in platinum resistance. The lncRNA ZFAS1 enhances cisplatin resistance through regulating the miR-150-5p/SP1/copper transporter 1 (CTR1) axis. Nuclear-enriched abundant transcript 1 (NEAT1) ameliorates platinum resistance via upregulating epigallocatechin-3-gallate (EGCG)-induced CTR1 expression. Metastasis-associated lung adenocarcinoma transcript 1 (MALAT1) and LINC00152 promote cisplatin resistance through activating MRP1. Homeobox transcript antisense RNA (HOTAIR) enhances platinum resistance via activating autophagy and Wnt/ $\beta$ catenin-induced epithelial-mesenchymal transition (EMT). The lncRNA H19 induces platinum resistance via enhancing the expression of nuclear factor erythroid 2 (NRF2) and glutathione (GSH), thereby preventing reactive oxygen species (ROS)-induced cytotoxicity. Moreover, H19 promotes platinum resistance by activating transcription factors involved in EMT.

\subsubsection{Intracellular Detoxification}

In the context of its mechanistic pathway, cisplatin not only interacts with purine nucleotides to activate DNA damage-induced apoptosis but also induces generation of ROS that participate in the platinum-induced cytotoxic effect [41,78]. Accordingly, regulation of the antioxidant system plays a substantial role in cisplatin resistance. Reduced GSH is a type of metallothionein that has a higher affinity to cisplatin than DNA $[40,79]$. Remarkably, elevated GSH level enhances cisplatin resistance, whereas depletion of GSH stores augments cisplatin chemosensitivity [80]. Moreover, upregulation of enzymes implicated in GSH synthesis and metabolism can mediate cisplatin resistance [50]. H19, also known as imprinted maternally expressed transcript, is an evolutionary conserved lncRNA expressed mainly in placental and fetal tissues, where it plays a fundamental role during embryogenesis [81]. It was reported that $H 19$ overexpression is positively correlated with cisplatin resistance in non-small cell lung cancer [82] and seminoma [83]. In OC, transcriptome sequencing elicited differential expression of H19 in cisplatin-resistant cells compared with wild-type cells. Additionally, the involvement of H19 in platinum resistance was evidenced in a study of tissues obtained from 41 high-grade serous carcinoma patients treated with either cisplatin or carboplatin; the results revealed that $H 19$ positively correlated with the early recurrence of OC [50]. Mechanistically characterized using proteomic analysis, it was 
shown that H19 knockdown reduces the expression of six NRF2-targeted proteins: NQO1, GSR, G6PD, GCLC, GCLM, and GSTP1. Nuclear factor erythroid 2 (NRF2) is a transcription factor that regulates the expression of multiple antioxidant enzymes, particularly those involved in the GSH metabolic pathway. Notably, the glutathione pathway plays a pivotal role in platinum resistance via counteracting platinum-induced oxidative cytotoxicity [84]. H19 is believed to enhance cisplatin resistance through activating GSH-dependent antioxidant activity, eventually abrogating cisplatin-induced oxidative cytotoxicity (Figure 3) [50].

\subsubsection{Regulation of Autophagy}

Autophagy is a conserved cellular process in which the cells degrade and remove dispensable or dysfunctional cytoplasmic components by the aid of lysosomal compartments. Autophagy plays a fundamental role in maintaining energy homeostasis, particularly during development and starvation [85]. Recently, multiple studies demonstrated that autophagy induces cisplatin resistance in cancer cells [86,87]. Yu et al. reported that lncRNA HOTAIR is overexpressed in OC and associated with cisplatin resistance [52]. Mechanistically, HOTAIR induced autophagy and increased cisplatin resistance through activating ATG7 [52]. ATG7 regulates autophagosome assembly via binding to and activating ubiquitin-like proteins such as ATG12 and ATG8 [88]. Similarly, HOTAIR promoted tumor growth and exacerbated cisplatin resistance via activating the Beclin-1/autophagy axis in endometrial cancer (EC) [53]. The X-inactive specific transcript (XIST) is an IncRNA identified within the region of chromosome $\mathrm{X}$ inactivation center (XIC) that plays a fundamental role in silencing one $\mathrm{X}$ chromosome during the developmental process in female fetuses [89]. It was reported that XIST is upregulated in non-small cell lung cancer tissues and positively correlated with autophagy and cisplatin resistance [90]. Functional analysis revealed that XIST knockdown increased cisplatin chemosensitivity and suppressed autophagy, and the administration of miR-17 inhibitor or upregulation of ATG7 reversed this action. These data proposed that XIST confers cisplatin chemoresistance, at least in part, through regulating the miR-17/ATG7 axis (Figure 3) [90].

\subsubsection{Epithelial-Mesenchymal Transition}

Epithelial-mesenchymal transition (EMT) is a reversible cellular process whereby epithelial cells lose cell polarity and cell-cell adhesion to adopt high migratory, spindle-shaped mesenchymal stem cells. EMT is important for numerous biological processes such as embryogenesis, development, wound healing, and cancer progression [91]. In the context of tumor progression, EMT can gain multiple traits that are important for tumor initiation, motility, metastasis, and the emergence of chemoresistance. Importantly, the presence of EMT-associated proteins can be exploited as highly specific predictors of high-grade malignancy [91,92]. EMT is orchestrated by certain transcription factors, including zinc-finger E-box-binding homeobox factors 1 and 2 (ZEB1 and ZEB2), SNAIL, SLUG, TWIST1, and TWIST2 $[93,94]$. These transcription factors are further regulated by particular upstream signaling pathways, including TGF- $\beta$, HIF1- $\alpha$, Wnt $/ \beta$-catenin, and Notch, and the dysregulation of these signaling cascades is associated with the emergence of platinum resistance $[9,95]$. It was reported that silencing HOTAIR enhanced cisplatin sensitivity in a mouse xenograft model of OC [55]. Mechanistically, this effect could be attributed to the reduced activity of the Wnt/ $\beta$-catenin-induced EMT [55]. As another example, overexpression of $H 19$ promoted tumor growth, migration, and cisplatin resistance in OC cells by triggering EMT, as indicated by reduced E-cadherin and increased TWIST, SLUG, and SNAIL mRNA and protein levels (Figure 3) [51].

\subsubsection{Repair of Damaged DNA}

DDR comprises a network of multiple signaling pathways that orchestrate DNA repair in response to DNA damage to prevent the development of potentially harmful mutations [96]. The DDR signaling network generally includes the classic tumor suppressor gene TP53, its downstream target $p 21$, and nuclear factor kappa B (NF- $\mathrm{kB})$. In the setting of cancer, DDR activation promotes cancer cell 
survival and confers resistance to chemotherapy [96,97]. Since platinum compounds exert their major cytotoxic action by inducing DNA damage, cells that acquire high potential for repairing or preventing DNA damage can develop platinum resistance. Remarkably, DNA damage triggers the release of p53-dependent pro-apoptotic factors, and therefore decreased activity of p53 or its downstream signaling pathway can contribute to platinum resistance [98]. It was demonstrated that HOTAIR induces cisplatin resistance in OC via activating DDR. Mechanistically, NF- $\mathrm{KB}$ directly enhances HOTAIR expression in OC cell lines following cisplatin-induced-DNA damage. Subsequently, HOTAIR acts in a positive feedback loop to trigger persistent NF-kB activation, IL-6 secretion, and CHK1-p53-p21 pathway stimulation. Consequently, these effects drive the establishment of OC senescence and emergence of chemoresistance. The authors speculated that HOTAIR could be used as a new therapeutic strategy to improve platinum resistance in OC [56]. GAS5, also known as growth arrest-specific transcript 5, is a tumor suppressor gene located at chromosome 1q25 and encodes an lncRNA [99]. Dysregulation of GAS5 has been reported in various tumors, including lung [100], cervical [101], liver [102], and breast cancers [103]. In OC, GAS5 has been shown to inhibit tumor growth and inversely correlate with cisplatin resistance. In addition, GAS5 overexpression induced G0/G1 cell cycle arrest, apoptosis and cisplatin chemosensitivity, indicating its tumor suppressor effect. Mechanistic analysis revealed that GAS5 inhibits PARP1 expression via recruiting the E2F4 transcriptional factor to the promoter region of the PARP1 gene [48]. In the context of biological function, PARP1 plays an important role in genomic stability via regulating DNA repair, cell cycle progression, the evasion of apoptosis, and the activation of the mitogen-activated protein kinase (MAPK) downstream signaling pathway [104]. As a consequence of PARP1 inhibition, GAS5 overexpression inhibited the phosphorylation of extracellular signal-regulated kinase (ERK), jun N-terminal kinase (JNK), and MAPK, suggesting that GAS5 inhibits tumor growth and abrogates cisplatin resistance via regulating the E2F4-PARP1-MAPK signaling pathway (Figure 4) [48].



Figure 4. IncRNAs regulate platinum resistance via modulating DNA-damage-induced apoptosis. Growth arrest-specific transcript 5 (GAS5) mitigates cisplatin resistance via inhibiting PARP1-induced DNA repair. Colon cancer-associated transcript 1 (CCAT1) promotes platinum resistance through sponging miR-454, thereby activating survivin and inhibiting apoptosis. HOTAIR exacerbates platinum resistance through activating NF- $\mathrm{kB}$, leading to increased expression of survival genes. IncRNAs promoter of CDKN1A antisense DNA damage activated RNA (PANDAR), E2F-mediated proliferation enhancing lncRNA (EPEL), and HOTAIR induce platinum resistance via inhibiting p53-induced apoptosis, while plasmacytoma variant translocation 1 (PVT1) inhibits platinum resistance via promoting p53-induced apoptosis. 


\subsubsection{Regulation of Apoptosis}

Apoptosis is an evolutionarily conserved process that occurs in both physiological and pathological conditions and results in cell death. Two main pathways of apoptosis have been identified, known as extrinsic and intrinsic [105]. The intrinsic or mitochondrial pathway is mainly regulated by the BCL-2 family that includes antiapoptotic proteins such as BCL-2 and BCL-XL and proapoptotic proteins such as BAX, BAK, BAD, and BIK [106]. Since platinum agents exert their action mainly by inducing DNA damage with subsequent activation of p53-induced apoptosis, the suppression of apoptosis accounts for the acquisition of platinum resistance [41]. Several reports indicated that certain lncRNAs inhibit p53-induced apoptosis leading to acquisition of resistance [41]. For example, the lncRNA PANDAR has been identified as the most overexpressed p53-dependent lncRNA regulated by drug-induced apoptosis [107]. PANDAR has been shown to augment cisplatin resistance via modulating the PANDAR/SFRS2/p53 feedback loop in the nucleus. Mechanistically, PANDAR-induced cisplatin resistance was mediated by the PANDAR-binding protein, SFRS2 (arginine/serine-rich 2). SFRS2 is a splicing factor that negatively regulates P53 and its phosphorylation at Serine 15 (Ser15) [108,109]. Accordingly, the PANDAR-SFRS2-p53 feedback axis markedly decreases the transactivation of p53-related pro-apoptotic genes and consequently triggers cisplatin chemoresistance [58]. E2F-mediated cell proliferation enhancing lncRNA (EPEL) was originally identified in lung cancer [110]. Zhao et al. reported that the plasma level of EPEL is elevated in endometrioid adenocarcinoma patients compared to healthy patients [59]. Mechanistically, the overexpression of EPEL markedly dampened the expression of p53, thereby conferring carboplatin resistance. Additionally, p53 overexpression did not alter EPEL expression level, suggesting that EPEL is an upstream inhibitor of p53 [59]. In a similar way, a study has been conducted to determine the effect of the carboplatin/docetaxel combination on the expression levels of several lncRNAs in an OC cell line, 3AO [60]. Among 30 tumor-related lncRNAs, only 10 different lncRNAs showed significant alterations in response to carboplatin/docetaxel treatment. These 10 lncRNAs include PVT1, TDRG1, PCAT1, GAS5, HOTAIR, SRA1, BCYRN1, CASC2, HI9, and MEG3. The first six lncRNAs were upregulated while the last four were downregulated following carboplatin/docetaxel treatment. The six upregulated lncRNAs were silenced by using their specific siRNAs, and only siRNA/PVT1 showed increased cell proliferation when combined with docetaxel/carboplatin treatment, indicating that carboplatin/docetaxel combination induces PVT1 expression, which in turn could mediate the anticancer activity of the combined treatment. On a mechanistic level, PVT1 enhanced the expression level of both TIMP1 and p53. TIMP1, also called tissue inhibitor of matrix metalloproteinase 1, inhibits the proteolytic activity of matrix metalloproteinases, eventually leading to the inhibition of tumor invasion and metastasis [111,112], whereas p53 regulates the cell cycle and thus functions as a tumor suppressor protein. Through upregulating TIMP1 and p53, lncRNA PVT1 improves sensitivity to carboplatin/docetaxel treatment and exerts direct tumor-suppressing action [60].

Colon cancer-associated transcript 1 (CCAT1) is an lncRNA mapped at chromosome 8q24.21 and has been initially identified as an oncogenic lncRNA in colorectal cancer [113]. Subsequent studies elucidated that CCAT1 is overexpressed not only in colorectal cancer but also in various types of cancers, such as liver, ovarian, lung, gastric, breast, and gallbladder cancers [114,115]. In OC, it was reported that CCAT1 is upregulated in cisplatin-resistant cells, A2780/CP and SKOV3/CP, and CCAT1 knockdown markedly enhanced cisplatin chemosensitivity via inducing apoptosis in vitro and in vivo [61]. Mechanistically, silencing CCAT1 significantly elevated the level of miR-454, decreased levels of anti-apoptotic proteins BCL-2 and survivin, and enhanced the level of pro-apoptotic protein BAX. Research using bioinformatics and dual luciferase reporter assay identified miR-454 as a direct target for CCAT1. This association was further proved through functional experiments in which miR-454 overexpression enhanced cisplatin cytotoxicity, whereas miR-454 inhibitors exacerbated CCAT1-induced cisplatin resistance-suggesting that CCAT1 enhances cisplatin resistance, at least in part, through modulating the miR-454/survivin axis [61]. In other research, LINC00152 was upregulated in cisplatin-resistant OC cells, and LINC00152 knockdown significantly abrogated cisplatin resistance 
via decreasing MDR1 and MRP1 mRNA levels and inducing apoptosis, as indicated by increased cleaved caspase 3 and BAX and reduced BCL-2 protein levels [62]. Other lncRNAs can affect cisplatin resistance through regulating apoptosis; however, the exact underlying mechanism for their action has not been revealed yet. For instance, PVT1 enhances [116], but ENST00000457645 reduces [66] cisplatin resistance in OC (Figure 4).

\subsubsection{Sponging miRNAs}

Several lncRNAs regulate gene expression by sequestering miRNAs and acting as competing endogenous RNAs (ceRNAs), eventually abrogating miRNA-induced gene silencing [36]. Urothelial carcinoma associated 1 (UCA1) is an oncogenic lncRNA associated with multiple malignancies including hepatocellular carcinoma, ovarian, bladder, breast, and colorectal cancers [117-121]. In OC, it was demonstrated that UCA1 is upregulated in cisplatin-resistant cells and patient tissues. Further mechanistic studies revealed that UCA1 exacerbates cisplatin resistance via regulating the miR-143/FOSL2 axis. Notably, miR-143 is a tumor suppressor that negatively correlates with cisplatin resistance and is believed to exert its action, at least in part, through silencing FOSL2 gene expression [63]. Fos-related antigen 2 (FRA-2/FOSL2) belongs to the AP-1 transcription factor family and plays a critical role in tumor growth and metastasis [122-124]. Dual-luciferase reporter and RIP assays identified the direct interaction between UCA1 and miR-143, indicating that UCA1 induces its effect via sponging miR-143 with a subsequent upregulation of its downstream target, FOSL2 [63]. Similarly, SNHG22 confers resistance to cisplatin and PTX via modulating miR-2467/Gal-1 signaling cascade [64]. Moreover, HOTAIR induces cisplatin resistance by sponging miR-138-5p, thereby halting its binding to EZH2 (enhancer of zeste 2 polycomb repressive complex 2 subunit) and SIRT1 (sirtuin 1) [54]. On the contrary, some lncRNAs may have tumor suppressor effects while their downstream target miRNAs may act as oncogenes. For instance, the overexpression of XIST suppressed tumor proliferation and invasion, and enhanced cisplatin chemosensitivity in CAOV3 and OVCAR3 OC cell lines as well as a xenograft mouse model and this antineoplastic effect was attributed to sponging the oncogenic miR-214-3p [125]. Other lncRNAs such as LINC01125 enhances cisplatin and PTX chemosensitivity through regulating the miR-1972/apoptosis pathway [65].

\subsubsection{Other lncRNAs Implicated in Platinum Resistance}

Teschendorff et al. reported that OC patients overexpressing HOTAIR, or an equivalent HOTAIR-associated DNA methylation, develop carboplatin resistance and are associated with poor survival outcome [57]. Accordingly, the authors speculated that HOTAIR could be used as both a biomarker and a therapeutic target in carboplatin resistance [57]. Furthermore, it was reported that the plasma level of CASC11 is elevated in ovarian squamous cell carcinoma patients compared to healthy women. Importantly, the plasma level of CASC11 was measured before, 3 and 6 months after initiating chemotherapy (cisplatin, carboplatin, oxaliplatin, and tetraplatin) and the results revealed that the plasma level of CASC11 was significantly elevated after chemotherapy treatment. By applying the UWB1.289 cell line, silencing CASC11 improved the sensitivity of the four agents, suggesting that CASC11 may serve as a potential target to improve therapeutic response [68]. IncRNA BC200, also known as BCYRN1, has been originally identified as a brain-specific cytoplasmic ncRNA that contains 200 nucleotides [126]. Wu et al. explored the role of BC200 in ovarian tissues derived from both 10 normal and 12 OC patients. The results showed that $\mathrm{BC} 200$ was downregulated in OC tissues compared to normal samples. Likewise, carboplatin treatment induced BC200 expression and silencing BC200 significantly promoted proliferation and enhanced carboplatin resistance in both SKOV3 and A2780 cell lines [67]. Other lncRNAs, such as SNHG15, were also associated with proliferation, invasion, metastasis, and cisplatin resistance in OC; however, the exact mechanism that accounts for such an effect remains elusive [69]. 


\subsection{IncRNAs and Taxanes Resistance}

Taxanes exhibit unique pharmacological features as inhibitors of mitosis by binding to the $\beta$ II subunit of tubulin dimers to promote, rather than suppress, microtubule polymerization. This unique mechanism blunts microtubule disassembly, a necessary event in cell division, ultimately leading to mitotic arrest and apoptosis [127]. PTX and its congener, docetaxel, are considered the mainstay for the treatment of different tumors including head and neck, ovarian, breast, gastrointestinal, and lung cancers [128]. In OC, PTX is used mainly combined with a platinum-based agent as a first-line treatment, or as a single antineoplastic agent in platinum-resistant patients. However, the emergence of resistance is the major limitation for the successful use of taxanes in OC [9]. Thus, understanding the molecular mechanisms encountered in taxanes resistance is critical to improve therapeutic intervention. Notably, the general mechanisms of resistance include increased expression of the MDR-1 gene and its related product P-glycoprotein, the development of $\beta$ II-tubulin mutations, the upregulation of $\beta$ III-isoform of tubulin, and increased production of survivin, an antiapoptotic protein, and $\alpha$ aurora kinase, an enzyme that enhances accomplishment of mitosis $[129,130]$. Unlike platinum compounds, the studies investigating the role of lncRNAs in the emergence of taxanes resistance in OC are few, probably due to the rare use of taxanes as a single agent in OC. Here, we collected the substantial studies exploring the role of lncRNAs in the development of taxanes resistance. A list of lncRNAs associated with taxane resistance is summarized in Table 2. Besides, the molecular mechanisms implicated in taxanes resistance are illustrated in Figure 5.

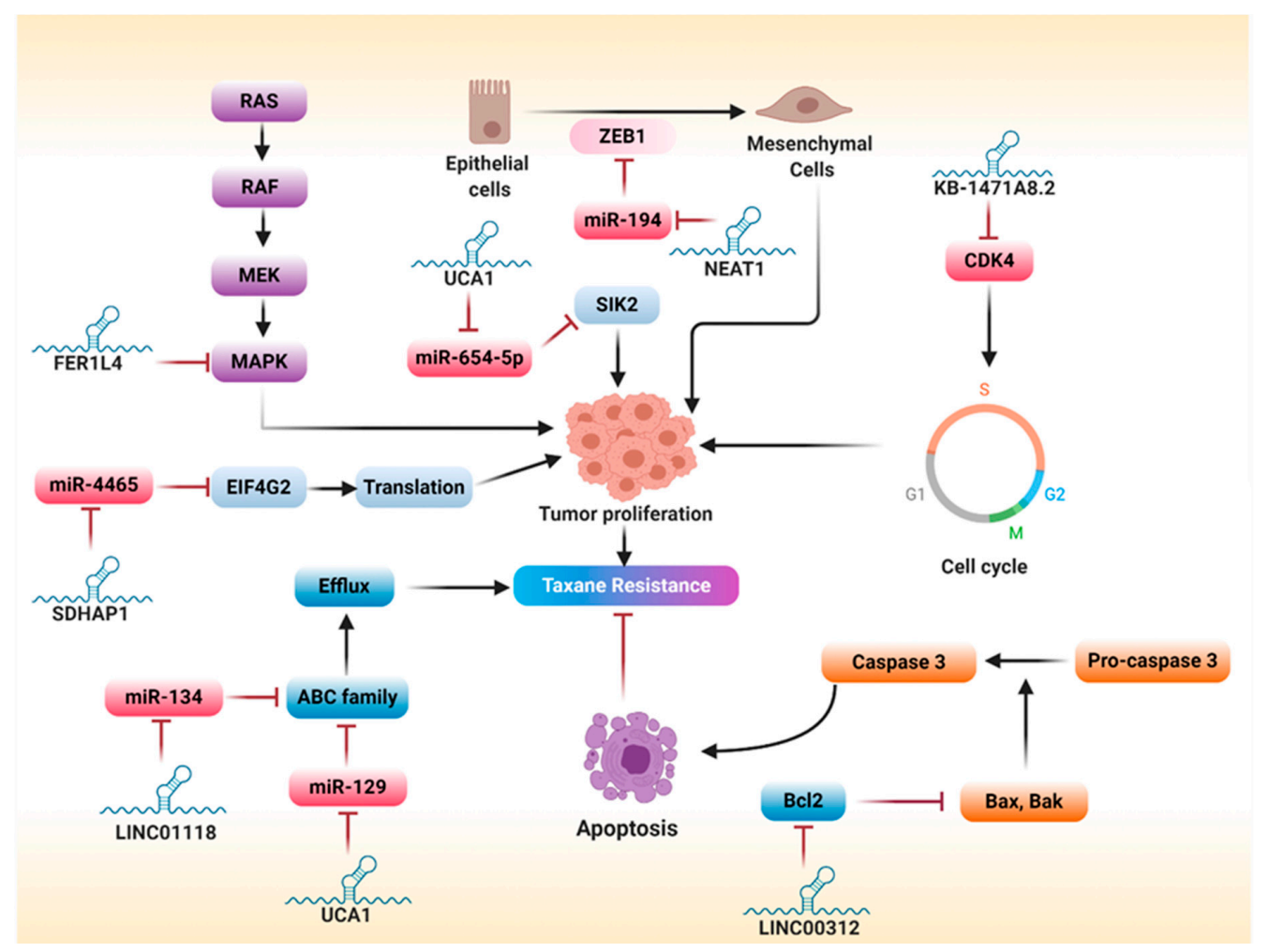

Figure 5. Major lncRNAs involved in taxane resistance. LINC01118 and urothelial carcinoma associated 1 (UCA1) promote taxane resistance via activating ATP-binding cassette (ABC) family and drug efflux. Linc00312 circumvents taxane resistance through suppressing $\mathrm{Bcl} 2$ and inducing apoptosis. Succinate dehydrogenase complex, subunit A, flavoprotein pseudogene 1 (SDHAP1) promotes taxane resistance via sponging miR-4465, consequently enhancing EIF4G2 and initiating protein translation. FER1L4 mitigates taxane resistance by suppressing the mitogen-activated protein kinase (MAPK) pathway. UCA1 promotes taxane resistance by regulating the miR-654-5p/SIK2 axis. NEAT1 promotes taxane resistance via sponging miR-194, thereby activating ZEB1 and EMT. KB-1471A8.2 ameliorates taxane resistance by blocking CDK4 and S-phase entry. 
Table 2. List of lncRNAs associated with taxane resistance.

\begin{tabular}{|c|c|c|c|c|c|}
\hline Name of lncRNA & Classification & Type of Cancer & Role in Drug Resistance & Mechanism & Reference \\
\hline UCA1 (urothelial carcinoma associated 1) & Intergenic & Ovarian cancer & $\uparrow$ PTX resistance & $\begin{array}{c}\text { Sponging miR-129 } \rightarrow \uparrow \text { ABCB1-induced drug efflux } \\
\text { Regulating miR-654-5p/SIK2 axis }\end{array}$ & $\begin{array}{l}{[131]} \\
{[132]}\end{array}$ \\
\hline LINC01118 & Intergenic & Ovarian cancer & $\uparrow$ PTX resistance & Regulating miR-134/ABCC1 axis & [133] \\
\hline $\begin{array}{l}\text { NEAT1 (nuclear paraspeckle assembly } \\
\text { transcript 1) }\end{array}$ & Intergenic & Ovarian cancer & $\uparrow$ PTX resistance & Sponging miR-194 $\rightarrow \uparrow$ ZEB1 expression $\rightarrow \uparrow$ EMT & [134] \\
\hline $\begin{array}{l}\text { NEAT1 (nuclear paraspeckle assembly } \\
\text { transcript 1) }\end{array}$ & Intergenic & Endometrial cancer & $\uparrow$ PTX resistance & Sponging miR-194 $\rightarrow \uparrow \mathrm{STAT} 3$ expression & [135] \\
\hline SNHG5 (small nucleolar RNA host gene 5) & Intergenic & Ovarian cancer & $\downarrow$ PTX resistance & Sponging oncogenic miR-23a & [136] \\
\hline $\begin{array}{l}\text { SDHAP1 (succinate dehydrogenase complex, } \\
\text { subunit A, flavoprotein pseudogene 1) }\end{array}$ & Pseudogene & Ovarian cancer & $\uparrow$ PTX resistance & Regulating miR-4465/EIF4G2 axis & [137] \\
\hline $\begin{array}{l}\text { HEIH (highly expressed in } \\
\text { hepatocellular carcinoma) }\end{array}$ & Intergenic & Endometrial cancer & $\uparrow$ PTX resistance & Activating MAPK pathway & [138] \\
\hline FER1L4 (fer-1 like family member 4) & Pseudogene & Ovarian cancer & $\downarrow$ PTX resistance & $\downarrow$ Phosphorylation of MAPK & [139] \\
\hline $\begin{array}{l}\text { LINC00312 (long intergenic non-protein } \\
\text { coding RNA 312) }\end{array}$ & Intergenic & Ovarian cancer & $\downarrow$ PTX resistance & $\begin{array}{l}\text { Blocking BCL-2 expression and activating } \\
\text { Bax/Caspas3 apoptotic pathways }\end{array}$ & [140]. \\
\hline $\begin{array}{l}\text { ANRIL (antisense non-coding RNA in the } \\
\text { INK4 locus) }\end{array}$ & Antisense & Endometrial cancer & $\uparrow$ PTX resistance & $\begin{array}{l}\text { Regulating both miR-125a-5p/Bcl2 and } \\
\text { miR-125a-5p/MRP4 axes }\end{array}$ & [141] \\
\hline KB-1471A8.2 & Antisense & Ovarian cancer & $\downarrow$ PTX resistance & Blocking S-phase entry and CDK4 & [142] \\
\hline CTD-2589M5.4 & Intergenic & Ovarian cancer & $\begin{array}{l}\text { Associated with } \\
\text { multidrug resistance }\end{array}$ & $\begin{array}{l}\text { Unknown but may be related to } \mathrm{ABCB} 1, \mathrm{ABCB} 4 \\
\qquad \mathrm{ABCC} 3 \text {, and } \mathrm{ABCG} 2\end{array}$ & [143] \\
\hline
\end{tabular}

The arrows in this table refer to: $\uparrow$ (increase); $\downarrow$ (decrease); $\rightarrow$ (leading to). 


\subsubsection{Increased Drug Efflux}

A study was conducted to explore the association of particular lncRNAs in the emergence of multidrug resistance (PTX, cisplatin, and epirubicin) in both OC and colorectal cancer via using both lncRNA sequencing and bioinformatics analysis [143]. The results identified five upregulated and 21 downregulated lncRNAs as multidrug resistant. Of those lncRNAs, OIP5-AS1 was downregulated in both ovarian and colorectal cancer cell lines, whereas RFPL1S, ZEB1-AS1, and C17orf82 were downregulated in only OC cells with no significant changes in colorectal cancer cell lines, suggesting that MDR-related lncRNAs have both specific and conservative functions among different types of cancers. Additionally, an lncRNA-mRNA co-expression network revealed that lncRNA CTD-2589M5.4 is upregulated in multidrug-resistant cells and co-expressed with multidrug-resistant genes $A B C B 1$, $A B C B 4, A B C C 3$, and $A B C G 2$, advocating its significant role in the development of multidrug resistance [143]. Although this study showed the specific and conservative nature of MDR-linked lncRNAs in ovarian and colorectal cancers, it did not prove whether MDR-linked lncRNAs are the major driver for the emergence of chemoresistance. Thus, further mechanistic studies are needed to explore such an approach. Wang et al. showed that UCA1 confers resistance to PTX in OC cells, and this action could be attributed to the suppression of miR-129, a tumor suppressor miRNA. As a part from its action, miR-129 attenuates tumor growth by silencing the expression of $A B C B 1$. Accordingly, UCA1 conveyed resistance to PTX through sponging miR-129, which in turn exacerbated ABCB1-induced drug efflux [131]. Other lncRNAs, such as LINC01118, have been reported to promote PTX resistance via regulating the miR-134/ABCC1 axis [133].

\subsubsection{Epithelial-Mesenchymal Transition}

NEAT1, a nuclear-restricted lncRNA, positively regulates tumorigenesis in different solid tumors [144]. It was reported that NEAT1 is overexpressed in PTX-resistant OC tissues and cells [134]. Further mechanistic analyses revealed that NEAT1 mediates PTX resistance via upregulating ZEB1 expression by sponging miR-194, a tumor suppressor miRNA. Interestingly, miR-194 knockdown or NEAT1 overexpression markedly abrogated the beneficial effects of ZEB1-knockdown on PTX resistance, indicating that ZEB1 is a potential downstream target of NEAT1 and miR-194 [134]. In conclusion, since ZEB1 is a transcription factor that favors EMT, NEAT1 enhances PTX resistance via activating EMT.

\subsubsection{Regulation of Survival Pathways}

Activation of survival pathways is a common mechanism by which various lncRNAs can induce chemoresistance. Of those, the ERK pathway was involved in lncRNA-mediated PTX resistance. Generally, the pathway structure includes a small G protein (RAS) and three protein kinases (RAF, MEK, ERK). Activation of this pathway culminates with the translocation of ERK into the nucleus, with a subsequent activation of transcription factors implicated in gene expression and survival [145]. Several reports have shown the relationship between lncRNAs and MAPK pathways in the emergence of PTX resistance. For example, hepatocellular carcinoma upregulated EZH2-associated lncRNA (HEIH), initially identified in hepatocellular carcinoma, promotes tumor growth through suppressing cell differentiation in the G0/G1 phase [146,147]. Guo et al. elucidated that HEIH is upregulated in EC cells and associated with increased PTX resistance [138]. Furthermore, HEIH knockdown dampened tumor proliferation and improved PTX chemosensitivity via blocking the activation of the MAPK signaling pathway [138]. Several lncRNAs have been reported to act as tumor suppressor genes. Of those, lncRNA fer-1-like family member 4 (FER1L4) is downregulated in several cancers, including osteosarcoma [148], esophageal cancer [149], endometrial cancer [150], hepatocellular carcinoma [151], and gastric cancer [152]. Liu et al. showed that FER1L4 expression is reduced in OC cell lines, particularly those resistant to PTX, and overexpression of FER1L4 promotes PTX sensitivity and reduce proliferation [139]. Mechanistically, overexpression of FER1L4 inhibits the phosphorylation MAPK. Additionally, treatment with SB203580, a suppressor of the p38 MAPK pathway, markedly improved 
PTX sensitivity, suggesting that FER1L4 improves PTX sensitivity via blocking activation of the MAPK pathway [139].

\subsubsection{Regulation of Apoptosis}

Various lncRNAs regulate the emergence of chemoresistance via modulating apoptosis. For instance, LINC00312 was shown to counteract PTX resistance in OC and enhance apoptosis via blocking BCL-2 and activating the Bax/Caspas3 apoptotic pathway [140]. Another lncRNA, CDKN2B-AS, also called antisense ncRNA in the INK4 locus (ANRIL), is overexpressed in a wide array of solid tumors such as hepatocellular carcinoma [153] and cervical [154], breast [155], endometrial, and prostate cancers [156]. In EC, CDKN2B-AS is upregulated in EC tissues and cells and positively correlated with a high pathological grade of EC and PTX resistance [141]. Likewise, silencing CDKN2B-AS attenuated PTX resistance and enhanced miR-125a-5p expression in EC cells. miR-125a-5p belongs to the miR-125 family and negatively regulates tumorigenesis [157,158]. Mechanistically, CDKN2B-AS induces chemoresistance via regulating the miR-125a-5p/BCL2 and miR-125a-5p/MRP4 network [141].

\subsubsection{Regulation of Cell Cycle}

Since taxanes are mitotic (M) phase-specific, the regulation of cell cycle plays a fundamental role in taxanes resistance. Zhang et al. demonstrated that lncRNA KB-1471A8.2 is downregulated in OC cells, particularly those resistant to PTX [142]. Moreover, the overexpression of KB-1471A8.2 attenuated cell proliferation, migration, and invasion and enhanced apoptosis and PTX sensitivity in OC cells. Mechanistically, given that PTX exerts its anticancer effect through inhibiting mitosis and inducing apoptosis, KB-1471A8.2 has been shown to improve PTX sensitivity by inhibiting S-phase entry and cyclin-dependent kinase 4 (CDK4) [142]. However, more studies are needed to reveal the full mechanistic pathway encountered in PTX resistance in OC.

\subsubsection{Sponging miRNAs}

Small nucleolar RNA host gene 5 (SNHG5) is an lncRNA whose gene is located at the chromosomal translocation breakpoint involved in B-cell lymphoma [159]. According to data obtained from TCGA, SNHG5 is downregulated in OC patients, particularly those resistant to PTX, and its downregulation is associated with poor survival and cancer progression [136]. Functional studies revealed that overexpression of SNHG5 dramatically enhanced the PTX sensitivity and suppressed tumor growth in vitro and in vivo. On a mechanistic level, SNHG5 exacerbated PTX sensitivity through acting as a decoy for miR-23a, an oncogenic miRNA overexpressed in multiple tumors [160,161]. Accordingly, this study speculated that the SNHG5/miR-23a axis could be used as a potential target for improving PTX sensitivity in OC [136]. Another study demonstrated that UCA1 enhances proliferation, migration, invasion, and PTX resistance, and this action could be attributed to the regulation of the miR-654-5p/SIK2 axis [132]. Mechanistically, UCA1 acts as a sponge for miR-654-5p, and the knockdown of UCA1 augmented the inhibitory effect of miR-654-5p on the development of OC [162]. Additionally, overexpression of miR-654-5p ameliorated PTX resistance via blunting the expression of salt inducible kinase 2 (SIK2). SIK2 is a member of the adenosine $5^{\prime}$-monophosphate-activated protein kinase (AMPK) subfamily that positively regulates tumor growth and metastasis $[163,164]$. Remarkably, silencing SIK2 improved PTX sensitivity and inhibited tumor growth, and this action was abolished by miR-654-5p inhibition, suggesting that SIK2 is a downstream target of UCA1/miR-654-5p [132]. Similarly, lncRNA SDHAP1 was reported to promote PTX resistance via regulating the miR-4465/EIF4G2 axis [137]. Moreover, Dong et al. investigated the mechanistic pathway underlying the action of NEAT1 in EC [135]. Functional assays showed that silencing NEAT1 markedly mitigated proliferation, invasion, and sphere formation and improved PTX sensitivity in EC. Mechanistically, NEAT1 induces its action via regulating the miR-361/STAT3 axis. Importantly, miR-361 attenuates proliferation, invasion, and PTX resistance by silencing signal transducer and activator of transcription 3 (STAT3) [135]. STAT3 is a transcription factor that positively regulates carcinogenesis [135]. Moreover, NEAT1-induced 
inhibition of miR-361 activates not only the STAT3 pathway but also several prometastatic and tumor microenvironment-related genes such as MEF2D, ROCK1, WNT7A, and KPNA4. These genes play a fundamental role in the acquisition of metastatic potential and PTX resistance in EC cells. Therefore, targeting NEAT1 could be a promising approach for improving therapeutic response to PTX [135].

\subsubsection{Other lncRNAs Implicated in Paclitaxel Resistance}

A comprehensive study has been conducted to reveal the expression profile of lncRNAs associated with PTX resistance in OC tissues and cell lines. The findings of this study identified seven lncRNAs aberrantly expressed in PTX-resistant phenotypes: XR_938392, XR_947831, XR_948297, XR_938728, NR_073113, NR_103801, and NR_036503. Furthermore, functional analysis revealed that the signature for these lncRNAs is positively correlated with a bundle of 129 genes implicated in insulin secretion-related pathway. Consequently, the authors speculated that those lncRNAs regulate tumor proliferation and chemoresistance via an interplay between cancer-related pathways and insulin secretion and that these lncRNAs could be used as predictive biomarkers for PTX resistance in OC patients [165]. However, more studies need to be conducted to validate the use of these lncRNAs as predictive biomarkers for PTX resistance in OC and to explore the underlying mechanistic circuitries of the correlation between these lncRNAs and chemoresistance. Another study has identified a strong correlation between XIST RNA expression and PTX sensitivity in OC, suggesting that XIST could be used as a prognostic biomarker for chemosensitivity in OC [166]. However, this study lacked the potential mechanism for such a correlation, which warrants further investigation.

\section{Therapeutic Approaches for Targeting lncRNAs}

Several lncRNAs significantly modulate tumorigenesis and chemoresistance and could be used as therapeutic targets in clinical settings. For a successful translation into the clinic, novel effective approaches for targeting lncRNAs should be established. Currently, multiple strategies can be used to effectively target lncRNAs, including (1) the post-transcriptional degradation of lncRNAs, (2) the modification of lncRNA genes, (3) and the loss of lncRNAs' function [167].

Post-transcriptional targeting of IncRNAs relies on nucleic acid-based modalities that have the ability to target any unique portion of the transcriptome, thereby affecting the "undruggable" parts of the entire genome. Presently, there are two major strategies harnessing nucleic acid-based techniques: double-stranded RNA-mediated interference (RNAi) and single-stranded antisense oligonucleotides (ASOs). RNAi comprises application of siRNA, a short dsRAN molecule, approximately 21-23 nucleotides in length, that interacts with and activates the RNA-induced silencing complex (RISC). Importantly, the endonuclease component of the RISC, named Argonaute 2 (Ago2), cleaves the sense strand of siRNA, enabling the antisense strand to bind to mRNA in a complementary manner, leading to mRNA degradation [168]. Since double-stranded RNAs are inherently vulnerable to degradation by nucleases, chemical modifications are required to protect them. Among these modifications, the addition of $2^{\prime}-\mathrm{O}$ methyl ( $\left.2^{\prime}-\mathrm{O}-\mathrm{Me}\right)$ sugar residues and phosphorothioate linkages on the $3^{\prime}$ end of the RNA markedly improves the pharmacological features of siRNA-based approaches [169]. Although numerous in vitro studies have been conducted via using RNAi as a tool for targeting lncRNAs, the use of siRNA/shRNAs in preclinical studies is challengeable due to poor bioavailability and ineffective delivery methods [167]. Unlike RNAi, ASO is a single-chain oligonucleotide that binds to RNA through Watson-Crick base pairing, resulting in activation of an RNase H-dependent cleavage mechanism, eventually leading to endo-nucleolytic cleavage of RNA [167]. The advances in ASO chemistry have led to a great impact on improving the overall pharmacological properties of ASOs via protecting them from cleavage by nucleases, enhancing binding affinity, and optimizing pharmacokinetic features [170,171]. Currently, ASOs have been involved in several clinical trials, and they are emerging as a promising therapeutic strategy for targeting lncRNAs [172].

The evolution of technology has led to the development of a highly advanced, versatile method for genome editing, known as the clustered regularly interspaced short palindromic repeats (CRISPR)-Cas 
system. This system consists of two fundamental parts: an enzyme called Cas and a predesigned RNA sequence named guide RNA. Cas has the ability to induce site-specific cleavage of DNA, while a guide RNA binds to both DNA strands in a complementary manner and directs the Cas enzyme to the right region of the genome [173]. By applying such technology into lncRNAs, it is feasible to induce silencing of lncRNA-expressing loci, thereby blocking lncRNA transcription. On a mechanistic level, dead-Cas9 is merged with transcriptional repressors and then directed into a specific gene promoter to block lncRNA transcription [174,175]. Furthermore, recent studies have identified CRISPR-Cas13 as another promising tool to block lncRNAs transcription [176]. Although the CRISPR-Cas approach is included in many preclinical studies, translation of this approach into the clinical setting warrants further investigation [167].

Emerging evidence reveals that certain lncRNAs exert their functions by forming secondary/tertiary structures or by binding to proteins. For instance, the $3^{\prime}$ ends of NEAT1 and MALAT1 form tertiary structures by folding into a unique triple helical structure [167,177]. In addition, numerous nuclear IncRNAs bind to chromatin-modifying complexes and regulate chromatin remodeling. Given these lncRNA functions, a new strategy has been evolved to prevent either lncRNA-protein interaction or formation of lncRNA secondary/tertiary structures. In this setting, specific types of ASOs that cannot stimulate RNAse $\mathrm{H}$ activity can be used to bind specifically to lncRNA, consequently blocking lncRNA-protein interactions [167]. Moreover, small molecule inhibitors can be used to target unique structural components of lncRNAs required for forming secondary/tertiary structures, thereby destabilizing the transcript and blocking their functions; however, this feature needs further investigation [167].

Natural antisense transcripts (NATs) are a class of ncRNAs transcribed in an antisense direction of a protein-coding gene [178]. Importantly, these transcripts negatively regulate the expression of neighboring protein-coding genes via acting in cis. Hence, targeting NATs using ASOs results in the upregulation of the neighboring protein-coding genes [179]. Accordingly, silencing NATs neighboring tumor suppressor genes could lead to the upregulation of tumor suppressor molecules and therefore negatively regulate tumorigenesis [167]. For instance, ANRIL and P21-AS IncRNAs are located near critical tumor suppressor genes $C D K N 2 B$ and $C D K N 1 A$, respectively, and knockdown of these NATs could be a potential therapy to inhibit tumor growth in multiple malignancies $[167,180,181]$.

\section{IncRNAs as Diagnostic and Prognostic Biomarkers}

The discovery that several lncRNAs are over-expressed in different cancers and can predict poor prognosis has drawn an increasing attention given their potential to be used as a clinical tool in diagnosis and/or prognosis of OC. Multiple approaches such as microarray hybridization, quantitative reverse transcription polymerase chain reaction (qRT-PCR), FISH and genome-wide profiling have been utilized to determine the levels of lncRNAs in different biological samples and several lncRNAs have been functionally characterized [182]. Since they have a cancer-specific expression pattern, IncRNAs have a great potential not only as novel therapeutic targets, but also as diagnostic and/or prognostic biomarkers [183,184]. Our group recently reported that multiple genomic non-coding loci harboring human-specific/primate-specific motifs, named pyknons, are differentially transcribed between healthy and diseased tissues in chronic lymphocytic leukemia and colorectal cancer. Furthermore, multiple new loci whose expression correlates with the overall survival of colorectal cancer patients' have been identified, suggesting that pyknons could be used as a primate-specific biomarker $[183,184]$. Similarly, the identification of primate-specific lncRNAs could be used as diagnostic/prognostic biomarker for multiple cancers. Various reports indicated that lncRNAs are aberrantly expressed in OC patients and such dysregulated expression correlates with clinicopathological parameters, including metastasis, histological type, and tumor size [185]. In the context of histology, several lncRNAs are correlated with different epithelial subtypes, and therefore they can be used to distinguish between different types of OC [185]. For instance, Casc2 and FLJ3360, respectively, differentiate the serous and high-grade serous from the other subtypes $[186,187]$. Furthermore, SNHG15 was found to be highly expressed 
in patients with type II cancers than patients with type I cancers indicating that it could distinguish between type I and type II OC [69].

In addition to their diagnostic value, certain lncRNAs can be used to predict survival of OC patients based on differential expression levels in specific cohort studies, resulting in different survival outcomes between patients with high vs. low expression level of lncRNAs [185]. Recently, a meta-analysis has indicated that aberrant expression of lncRNAs is positively correlated with poor survival outcomes in OC. During this study, 11 lncRNAs, including NEAT1, HOTAIR, MALAT1, TC010441, ANRIL, AB073614, CCAT2, ZFAS1, UCA1, SPRY4-IT1, and HOXA11as, were significantly associated with reduced overall survival, progression-free survival, and disease-free survival in OC patients [188]. Similarly, Luo et al. revealed that upregulation of eight lncRNAs; HOTAIR, NEAT1, CCAT2, UCA1, C17orf91, ANRIL, TC0101441, and AB073614 and downregulation of 5 lncRNAs; ASAP1-IT1, AC104699.1.1, LINC00472, FAM215, and RP11-284N8.3.1 were correlated with poor prognosis in OC given a probability for harnessing these lncRNAs as potential prognostic biomarkers for OC [189]. An integrated competing endogenous RNA network analysis has been conducted via implementing RNA-sequencing of data retrieved from the TCGA database and GSE17260 dataset to identify the potential RNA signatures that can be used as prognostic biomarkers for recurrent OC. Three lncRNAs, WT1-AS, NBR2, and ZNF883, were highly correlated with recurrent OC, indicating that these lncRNAs could be used as prognostic biomarkers for recurrent OC [190].

As mentioned above, platinum- and taxane-based chemotherapy is still the cornerstone for the treatment of OC patients. However, the overall outcome is still unsatisfactory owing to the development of chemoresistance. Given the fact that lncRNAs play a substantial role in the emergence of acquired resistance to different chemotherapy, several lncRNAs can be utilized as a clinical tool for stratifying patients into responders and non-responders and therefore optimizing the overall response to chemotherapy. For instance, SNHG5 can be used as a predictor for paclitaxel resistance, while RP11-135L22.1 and LINC00515 are very effective regarding platinum resistance [69].

\section{Challenges for lncRNAs Applications in Cancer}

Although a growing body of evidence indicates the significant role of certain lncRNAs in cancer, we still face multiple challenges that may hamper the impact of lncRNAs in the field of cancer. Some of these challenges are linked to the intrinsic features of lncRNAs, whereas others are associated with the approaches harnessed to either accurately measure the levels of IncRNAs or effectively target lncRNAs [188]. One of the major challenges is that lncRNAs are expressed in lower level compared to protein-coding genes [189]. In fact, this low expression could be partially attributed to the specific pattern of lncRNAs expression in different cells and tissues. Although some scholars believe such a specific expression pattern is an advantageous, it seems to be one of the major challenges, at least experimentally, since low abundant genes need more sophisticated approaches for accurate quantification [190]. Thus, a larger sample size and/or advanced technology is required to accurately measure the expression level of lncRNAs, consequently minimizing the errors and optimizing the overall analysis process [191]. Interestingly, advances in research revealed an attractive technology, named lnc(RNA) capture sequencing, that has the ability to accurately detect the expression level of IncRNAs in different biological samples with high sensitivity and reproducibility [192]. This technology utilizes a predesigned biotinylated probe that specifically capture the (lnc)RNA of interest while depleting more abundant mRNAs from the sequencing library [193]. We think the development of such technologies, despite being expensive, may tackle this challenge enabling for accurate detection of lncRNAs in different biological samples.

As mentioned earlier, lncRNAs have the potential to be employed as a diagnostic or prognostic biomarker. Importantly, to be an effective biomarker, lncRNAs should be detected in different body fluids particularly plasma, urine, and cerebrospinal fluid. However, a major challenge has been raised toward lncRNAs that the majority of lncRNAs detected in plasma are partially or completely fragmented [194]. This fact leads the scientists to pay much attention for exploring alternative effective 
approaches for the detection of lncRNAs in different biological fluids [195]. One of these approaches is the detection of lncRNAs enclosed in extracellular vesicles, particularly exosomes $[195,196]$. Exosomes are cell-derived extracellular vesicles, surrounded by lipid bilayers, and commonly found in plasma, urine, and cerebrospinal fluid [195]. They represent an attractive source of diagnostic/prognostic biomarkers since they harbor a large variety of biomolecules, e.g., DNA and lncRNAs reflecting a real-time status for the original cells. Likewise, they can be retrieved in non-invasive manner, can protect lncRNAs from degradation by ribonuclease activity, have a higher concentration compared to circulating cancerous cells and nucleic acids, and can easily penetrate into different body fluids due to their small size [195]. Several studies highlighted the role of exosomal lncRNAs as a biomarker in cancer. For instance, Zaho et al. reported that the overexpression of lncRNA HOTTIP is associated with poor survival in gastric cancer patients and serum exosomal HOTTIP is more accurate, as a diagnostic biomarker, than the commonly used tumor biomarkers carcino-embryonic antigen and carbohydrate antigens19-9 and 72-4 [197]. Although exosomes have several features that render them as plausible diagnostic/prognostic biomarkers, the translation of exosomal lncRNAs as diagnostic biomarkers into the clinical setting remains challenging. The major challenges for exsosomal application are exosomal heterogeneity, discrepancies between in vivo and in vitro experiments, difficulty to determine their origin, and a lack of tumor specificity $[195,198]$. Whether exosomal or plasma lncRNAs can serve as diagnostic biomarkers warrants further investigations.

Another challenge that hinders the application of lncRNAs is that many lncRNAs are dispensable and lack a definitive function. Recently, a study has been conducted in zebrafish by selecting 25 lncRNAs based on specific features such as expression profiling, conservative expression or vicinity to developmental regulators [199]. These lncRNAs were further subjected to CRISPR-Cas9 to induce 32 deletion alleles. Interestingly, the extrapolation from the results assumed that the majority of zebrafish lncRNAs have no overt roles in terms of fertility, embryogenesis, and viability [199]. Whether such finding affects the application of lncRNAs in cancer, in general, and chemoresistance, in particular, warrants further investigations. However, the expression of lncRNAs has been shown to be species specific [200]. An across-mammalian-genomes analysis demonstrated that approximately $30 \%$ of lncRNA transcripts $(n=4546)$ are primate specific (human, macaque, chimp, marmoset, and orangutan) [201]. Another study has been conducted via characterizing human IncRNA expression patterns in nine tissues across six mammalian species and multiple individuals [202]. Interestingly, the extrapolation from the results showed that of the 1898 human lncRNAs expressed in nine tissues, orthologous transcripts for $80 \%$ in chimpanzee, $63 \%$ in rhesus, $39 \%$ in cow, $38 \%$ in mouse, and $35 \%$ in rat have been identified [202]. Recently, two primate-specific lncRNAs, N-BLR and FLANC, have been shown to be conserved in human and to play a significant role in the development of colorectal cancer $[203,204]$. Overall, we conjecture that such discrepancy in lncRNAs function could be attributed to poor conservation of lncRNAs among species and that the closer the species to human, the more conservative transcripts of lncRNAs. Larger comparative studies are highly recommended to further reveal such discrepancy.

Some limitations that may prevent the translation of lncRNAs into the clinic are related to lncRNA-targeting approaches. As elaborated earlier, the most common approaches for targeting lncRNAs are RNA-based therapy and a CRISPR Cas system. Although RNA-based drugs can be easily applied into the cells, their systemic administration is vulnerable to degradation by nucleases and can provoke immune response. Moreover, they cannot penetrate the cell membrane easily due to negatively charged structure and can produce off-target effects [205]. Nonetheless, a wide variety of delivery agents are in development to ensure the efficient uptake of oligonucleotides, and consequently minimizing systemic toxicity. Our group has developed a neutral nanoliposome, named 1,2-Dioleoyl-sn-Glycero-3-Phosphatidylcholine (DOPC), to deliver nucleic acid into target cells. Intriguingly, our results revealed that DOPC nanoliposome has a 10-fold higher efficiency in delivering nucleic acid compared to cationic liposomes [206]. Furthermore, our group are currently undergoing a phase I trial that studies the effect of EphA2 siRNA/DOPC liposomal formulation on treating patients 
with advanced or recurrent solid tumors. Another lncRNA-based therapeutic strategy that has the potential for clinical application is the use of a BC-819 plasmid/polyethylenimine (PEI) system. BC-819, also known as H19-DTA, is a DNA vector that encodes for Diphtheria Toxin A fragment (DTA) under the control of $\mathrm{H} 19$ gene promoter (BC-819 or DTA-H19), whereas PEI is a transfection agent. This strategy is based on the fact that H19 lncRNA is overexpressed in malignant cells with minimal expression in normal cells, and, therefore, only malignant cells have the ability to activate $\mathrm{H} 19$ gene promoter and DTA production. Eventually, the resultant DTA disrupts protein synthesis and selectively destroys tumor cells. Clinical trials revealed that BC-819 administered locally in combination with systemic chemotherapy could improve therapeutic outcomes for the treatment of pancreatic, ovarian, or peritoneal cancer [207-209].

\section{Conclusions and Future Perspectives}

Dysregulation of lncRNAs can substantially trigger or ameliorate the emergence of resistance to platinum- and taxane-based chemotherapy in OC. On a mechanistic level, lncRNAs can modulate the response to chemotherapy via regulating drug uptake and efflux, intracellular drug detoxification, DNA damage repair, autophagy, apoptosis, EMT, cell cycle progression, and survival pathways. These findings can pave the path toward the use of an IncRNA-based approach for enhancing therapeutic response to platinum- and taxane-based chemotherapy in OC.

The use of lncRNA-based approach in OC is classified into diagnostic and therapeutic approaches. As diagnostic or prognostic tools, several lncRNAs can be implemented as prognostic biomarkers for both carcinogenesis and chemoresistance, given the facts that most lncRNAs have differential and specific expression, are stable in most body fluids like serum, urine, and saliva, and can be easily detected by experimental techniques such as microarray hybridization, qRT-PCR, and RNA sequencing. Although several lncRNAs are subjected to degradation by ribonucleases in plasma, exosomal lncRNAs are stable and could be used as diagnostic or prognostic biomarkers. However, the application of exosomes has several limitations such as tumor heterogeneity, lack of tumor specificity, and difficult isolation. Whether exosomal or plasma lncRNAs can serve as diagnostic biomarkers warrants further investigations. Advances in technology may provide a new technique for easily isolating and purifying exosomal lncRNAs that can be further utilized as unique biomarkers for individual cancers. Several characteristics are required for lncRNAs to be used as successful diagnostic and/or prognostic biomarkers. First, lncRNAs should exhibit a unique, specific signature for individual cancer types. Furthermore, they should occur in an early stage of cancer and show statistically significant expression compared to normal patients. In addition, they should be expressed in significant amounts that can be easily detected by quantitative methods. Finally, they should have standard normalization methods along with reliable internal controls.

The therapeutic approach is less advanced. Although the efficacy of certain lncRNAs as potential targets for ameliorating chemoresistance has been verified experimentally, the effective translation of these lncRNAs into clinical practice and the approval of lncRNA-targeting strategy have not been achieved yet. However, the use of DOPC nanoliposomal formulation and other neutral nanoliposomes could enhance the uptake of oligonucleotides into cancer cells, eventually leading to improved selectivity while minimizing systemic toxicity. Interestingly, our laboratory in collaboration with others are undergoing a clinical trial via harnessing DOPC nanoliposomal siRNA formulation for targeting EphA2 in OC and other solid tumors. This formulation could pave the path toward establishing a similar technique to target lncRNAs for therapeutic purpose. Moreover, the use of BC-819/PEI shows promising results when combined with $\mathrm{H} 19$ in pancreatic and OC clinical trials. Overall, we think that the development of an RNA-based drug to target particular lncRNA is plausible based on the previous research along with advances in technology.

The majority of studies investigating the role of lncRNAs in the emergence of chemoresistance encounter several limitations. First, these studies lack the detailed molecular mechanisms underlying the development of resistance. Second, most of these studies have been conducted using in vitro 
models only, while animal models or patient samples have not been investigated. Third, the translation of IncRNA-based approaches to circumvent chemoresistance will be hindered by poor sequence conservation among different species. In this setting, the lncRNAs that have been verified in mouse models may not be successfully translated into clinical application. Thus, considering these limitations, subsequent research should be directed toward the identification of additional lncRNAs along with investigating their roles in carcinogenesis and chemoresistance.

Despite the challenges facing lncRNAs, several approaches should be taken into consideration for optimizing lncRNA impacts on cancer. These approaches, from our perspective, include: (1) performing large projects for annotation and functional characterization of more lncRNAs in human; (2) detection of lncRNAs that show significantly aberrant expression in cancer vs. normal samples; (3) generating and unifying robust bioinformatic data that can be used as a tool for analyzing lncRNAs; (4) focusing on the highly conserved lncRNAs for further mechanistic studies; (5) testing the new delivering formulations that enhance selective uptake of RNA-based drugs in a large number of in vivo experiments; and (6) selecting the most promising lncRNAs for undergoing clinical trials in cancer patients.

Overall, accumulating evidence indicates that several lncRNAs are implicated in carcinogenesis and chemoresistance, and some of these IncRNAs can be implemented as either diagnostic biomarkers or therapeutic targets for chemoresistance in OC. Advances in technology may allow for effective translation of lncRNA-based therapeutic approaches into clinical practice.

Author Contributions: Conceptualization, A.M.E.; writing-original draft preparation, A.M.E.; writing-review and editing, P.A., S.A.S., A.H.A., G.L.-B. and C.R.-A.; supervision, P.A., S.A.S., A.H.A., G.L.-B. and C.R.-A. All authors have read and agreed to the published version of the manuscript.

Funding: This research was funded by NIH through the Brain SPORE Career Enhancement Program and NCI grant: P50CA127001; NIH through the Ovarian SPORE Career Enhancement Program and NCI grant: P50CA217685, to Paola Amero and Cristian Rodriguez-Aguayo. Abdelrahman M. Elsayed was supported by the Egyptian Ministry of Higher Education (EMHE).

Acknowledgments: We thank Bryan Tutt in Editing Services, Research Medical Library at MD Anderson Cancer Center for critical reading of the manuscript.

Conflicts of Interest: The authors declare no conflict of interest.

$\begin{array}{ll}\text { Abbreviations } & \\ \text { ABC } & \text { ATB binding cassette } \\ \text { AKT } & \text { Protein kinase B } \\ \text { Ago2 } & \text { Argonaute 2 } \\ \text { ASO } & \text { Antisense oligonucleotide } \\ \text { ATG7 } & \text { Autophagy related 7 homolog } \\ \text { BAD } & \text { Bcl2-associated death promoter } \\ \text { BAK } & \text { BCL-2 antagonist killer } \\ \text { BAX } & \text { BCL2-associated X protein } \\ \text { BCL-2 } & \text { B-cell lymphoma 2 } \\ \text { BCL-XL } & \text { B-cell lymphoma-extra-large protein } \\ \text { BIK } & \text { BCL-2 interacting killer } \\ \text { RAF } & \text { Rapidly accelerated fibrosarcoma } \\ \text { BRCA1/2 } & \text { Breast cancer susceptibility proteins 1 and 2 } \\ \text { CASC2 } & \text { Cancer susceptibility 2 } \\ \text { CDK4 } & \text { Cyclin dependent kinase 4 } \\ \text { CDKN1A (p21) } & \text { Cyclin dependent kinase inhibitor 1A } \\ \text { ceRNAs } & \text { Competitive endogenous RNAs } \\ \text { CHK1 } & \text { Checkpoint kinase 1 } \\ \text { CRISPR } & \text { Clustered regularly interspaced short palindromic repeats } \\ \text { CTNNB1 } & \text { Catenin beta 1 } \\ \text { CTR1 } & \text { Copper transporter 1 }\end{array}$




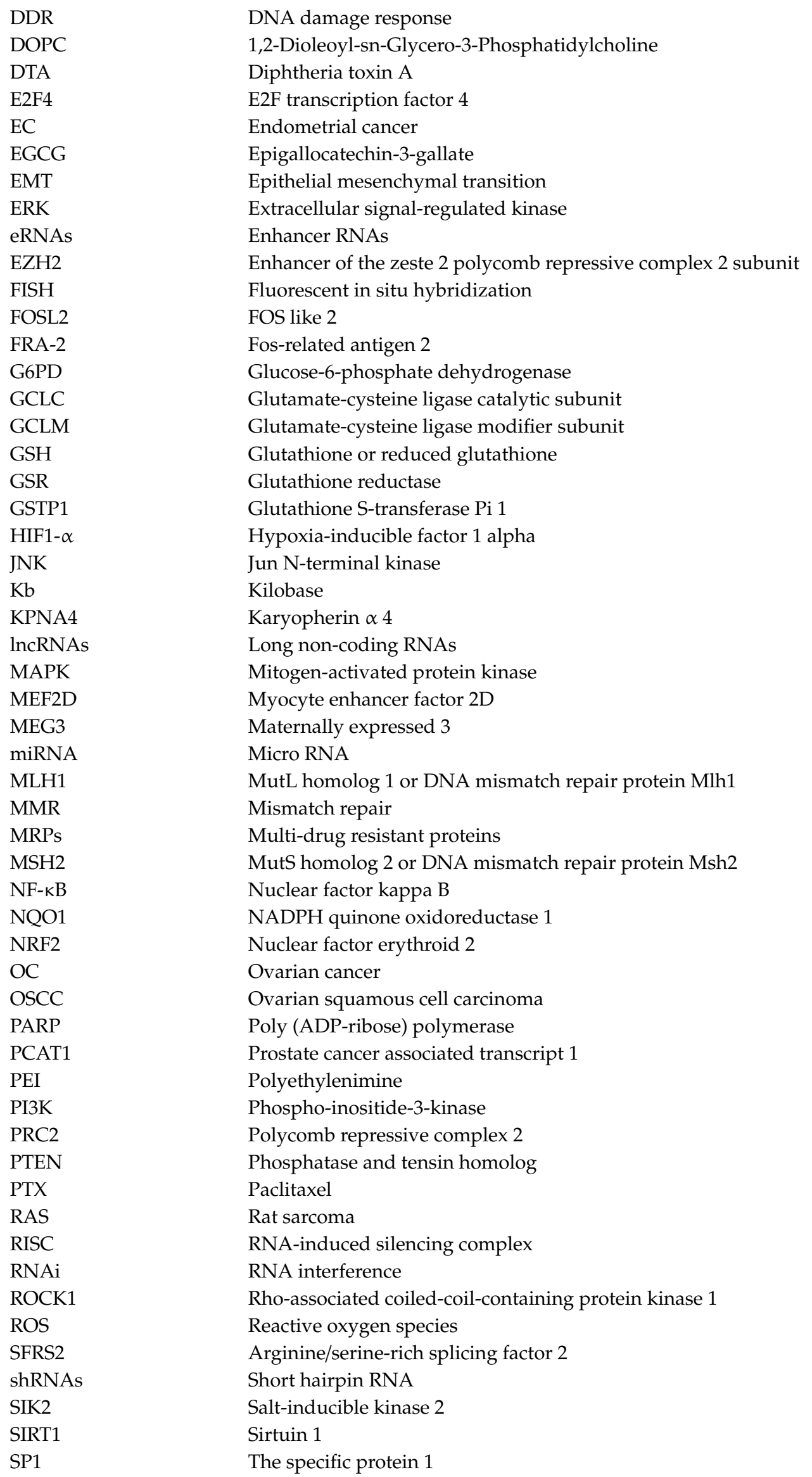


SRA1

STAT3

TDRG1

TGF- $\beta$

TIMP1

TP53

WNT7A

ZEB1
Steroid receptor RNA activator 1

Signal transducer and activator of transcription 3

Testis development related 1

Transforming growth factor beta 1

Tissue inhibitor of matrix metalloproteinase 1

Tumor protein 53

Protein Wnt-7a

Zinc finger E-box-binding homeobox 1

\section{References}

1. Coleman, R.L.; Monk, B.J.; Sood, A.K.; Herzog, T.J. Latest research and treatment of advanced-stage epithelial ovarian cancer. Nat. Rev. Clin. Oncol. 2013, 10, 211-224. [CrossRef] [PubMed]

2. Kurman, R.J.; Shih, I.-M. Pathogenesis of ovarian cancer. Lessons from morphology and molecular biology and their clinical implications. Int. J. Gynecol. Pathol. 2008, 27, 151. [PubMed]

3. Rosen, D.G.; Yang, G.; Liu, G.; Mercado-Uribe, I.; Chang, B.; Xiao, X.S.; Zheng, J.; Xue, F.X.; Liu, J. Ovarian cancer: Pathology, biology, and disease models. Front. Biosci. 2009, 14, 2089-2102. [CrossRef] [PubMed]

4. Ducie, J.; Dao, F.; Considine, M.; Olvera, N.; Shaw, P.A.; Kurman, R.J.; Shih, I.-M.; Soslow, R.A.; Cope, L.; Levine, D.A. Molecular analysis of high-grade serous ovarian carcinoma with and without associated serous tubal intra-epithelial carcinoma. Nat. Commun. 2017, 8, 1-9. [CrossRef] [PubMed]

5. Matulonis, U.A.; Sood, A.K.; Fallowfield, L.; Howitt, B.E.; Sehouli, J.; Karlan, B.Y. Ovarian cancer. Nat. Rev. Dis. Primers. 2016, 2, 16061. [CrossRef] [PubMed]

6. Kim, A.; Ueda, Y.; Naka, T.; Enomoto, T. Therapeutic strategies in epithelial ovarian cancer. J. Exp. Clin. Cancer Res. 2012, 31, 14. [CrossRef]

7. Djebali, S.; Davis, C.; Merkel, A.; Dobin, A.; Lassmann, T.; Mortazavi, A.; Tanzer, A.; Lagarde, J.; Lin, W.; Schlesinger, F.; et al. Landscape of transcription in human cells. Nature 2012, 489, 101-108. [CrossRef]

8. Palazzo, A.F.; Lee, E.S. Non-coding RNA: What is functional and what is junk? Front. Genet. 2015, 6, 2. [CrossRef]

9. Abildgaard, C.; Do Canto, L.M.; Steffensen, K.D.; Rogatto, S.R. Long non-coding RNAs involved in resistance to chemotherapy in ovarian cancer. Front. Oncol. 2019, 9, 1549. [CrossRef]

10. Iyer, M.K.; Niknafs, Y.S.; Malik, R.; Singhal, U.; Sahu, A.; Hosono, Y.; Barrette, T.R.; Prensner, J.R.; Evans, J.R.; Zhao, S. The landscape of long noncoding RNAs in the human transcriptome. Nat. Genet. 2015, 47, 199. [CrossRef]

11. Goff, L.A.; Rinn, J.L. Linking RNA biology to lncRNAs. Genome. Res. 2015, 25, 1456-1465. [CrossRef] [PubMed]

12. Anderson, D.M.; Anderson, K.M.; Chang, C.-L.; Makarewich, C.A.; Nelson, B.R.; McAnally, J.R.; Kasaragod, P.; Shelton, J.M.; Liou, J.; Bassel-Duby, R. A micropeptide encoded by a putative long noncoding RNA regulates muscle performance. Cell 2015, 160, 595-606. [CrossRef] [PubMed]

13. Marchese, F.P.; Raimondi, I.; Huarte, M. The multidimensional mechanisms of long noncoding RNA function. Genome. Biol. 2017, 18, 206. [CrossRef] [PubMed]

14. Gao, Y.; Li, X.; Zhi, H.; Zhang, Y.; Wang, P.; Wang, Y.; Shang, S.; Fang, Y.; Shen, W.; Ning, S. Comprehensive characterization of somatic mutations impacting lncRNA expression for pan-cancer. Mol. Ther. Nucleic Acids 2019, 18, 66-79. [CrossRef]

15. Oncul, S.; Amero, P.; Rodriguez-Aguayo, C.; Calin, G.A.; Sood, A.K.; Lopez-Berestein, G. Long non-coding RNAs in ovarian cancer: Expression profile and functional spectrum. RNA Biol. 2019, 1-12. [CrossRef]

16. Moran, V.A.; Perera, R.J.; Khalil, A.M. Emerging functional and mechanistic paradigms of mammalian long non-coding RNAs. Nucleic Acids Res. 2012, 40, 6391-6400. [CrossRef]

17. Khachane, A.N.; Harrison, P.M. Mining mammalian transcript data for functional long non-coding RNAs. PLoS ONE 2010, 5, e10316. [CrossRef]

18. Yu, A.D.; Wang, Z.; Morris, K.V. Long noncoding RNAs: A potent source of regulation in immunity and disease. Immunol. Cell Biol. 2015, 93, 277-283. [CrossRef]

19. Guttman, M.; Rinn, J.L. Modular regulatory principles of large non-coding RNAs. Nature 2012, 482, 339-346. [CrossRef] 
20. Rinn, J.L.; Chang, H.Y. Genome regulation by long noncoding RNAs. Annu. Rev. Biochem. 2012, 81, $145-166$. [CrossRef]

21. Gudenas, B.L.; Wang, L. Prediction of LncRNA Subcellular Localization with Deep Learning from Sequence Features. Sci. Rep. 2018, 8, 16385. [CrossRef] [PubMed]

22. Khalil, A.M.; Guttman, M.; Huarte, M.; Garber, M.; Raj, A.; Morales, D.R.; Thomas, K.; Presser, A.; Bernstein, B.E.; Van Oudenaarden, A. Many human large intergenic noncoding RNAs associate with chromatin-modifying complexes and affect gene expression. Proc. Natl. Acad. Sci. USA 2009, 106, 11667-11672. [CrossRef] [PubMed]

23. Carlevaro-Fita, J.; Johnson, R. Global positioning system: Understanding long noncoding RNAs through subcellular localization. Mol. Cell 2019, 73, 869-883. [CrossRef] [PubMed]

24. Bouvrette, L.P.B.; Cody, N.A.; Bergalet, J.; Lefebvre, F.A.; Diot, C.; Wang, X.; Blanchette, M.; Lécuyer, E. CeFra-seq reveals broad asymmetric mRNA and noncoding RNA distribution profiles in Drosophila and human cells. RNA 2018, 24, 98-113. [CrossRef] [PubMed]

25. Cabili, M.N.; Dunagin, M.C.; McClanahan, P.D.; Biaesch, A.; Padovan-Merhar, O.; Regev, A.; Rinn, J.L.; Raj, A. Localization and abundance analysis of human lncRNAs at single-cell and single-molecule resolution. Genome Biol. 2015, 16, 20. [CrossRef]

26. Dong, Y.; Yoshitomi, T.; Hu, J.-F.; Cui, J. Long noncoding RNAs coordinate functions between mitochondria and the nucleus. Epigenet. Chromatin. 2017, 10, 41. [CrossRef]

27. Zeng, C.; Fukunaga, T.; Hamada, M. Identification and analysis of ribosome-associated lncRNAs using ribosome profiling data. BMC Genom. 2018, 19, 414. [CrossRef]

28. Lin, A.; Hu, Q.; Li, C.; Xing, Z.; Ma, G.; Wang, C.; Li, J.; Ye, Y.; Yao, J.; Liang, K. The LINK-A lncRNA interacts with PtdIns $(3,4,5)$ P 3 to hyperactivate AKT and confer resistance to AKT inhibitors. Nat. Cell Biol. 2017, 19, 238-251. [CrossRef]

29. Gezer, U.; Özgür, E.; Cetinkaya, M.; Isin, M.; Dalay, N. Long non-coding RNAs with low expression levels in cells are enriched in secreted exosomes. Cell Biol. Int. 2014, 38, 1076-1079. [CrossRef]

30. Zhu, S.; Li, W.; Liu, J.; Chen, C.-H.; Liao, Q.; Xu, P.; Xu, H.; Xiao, T.; Cao, Z.; Peng, J. Genome-scale deletion screening of human long non-coding RNAs using a paired-guide RNA CRISPR-Cas9 library. Nat. Biotechnol. 2016, 34, 1279. [CrossRef]

31. Li, D.; Zhang, J.; Wang, M.; Li, X.; Gong, H.; Tang, H.; Chen, L.; Wan, L.; Liu, Q. Activity dependent LoNA regulates translation by coordinating rRNA transcription and methylation. Nat. Commun. 2018, 9, 1-14. [CrossRef] [PubMed]

32. Wang, K.C.; Chang, H.Y. Molecular mechanisms of long noncoding RNAs. Mol. Cell 2011, 43, 904-914. [CrossRef] [PubMed]

33. Balas, M.M.; Johnson, A.M. Exploring the mechanisms behind long noncoding RNAs and cancer. Noncoding RNA Res. 2018, 3, 108-117. [CrossRef]

34. Gupta, R.A.; Shah, N.; Wang, K.C.; Kim, J.; Horlings, H.M.; Wong, D.J.; Tsai, M.-C.; Hung, T.; Argani, P.; Rinn, J.L. Long non-coding RNA HOTAIR reprograms chromatin state to promote cancer metastasis. Nature 2010, 464, 1071-1076. [CrossRef] [PubMed]

35. Fang, Y.; Fullwood, M.J. Roles, Functions, and Mechanisms of Long Non-coding RNAs in Cancer. Genom. Proteom. Bioinf. 2016, 14, 42-54. [CrossRef]

36. Yamamura, S.; Imai-Sumida, M.; Tanaka, Y.; Dahiya, R. Interaction and cross-talk between non-coding RNAs. Cell. Mol. Life Sci. 2018, 75, 467-484. [CrossRef]

37. Thomson, D.W.; Dinger, M.E. Endogenous microRNA sponges: Evidence and controversy. Nat. Rev. Genet. 2016, 17, 272. [CrossRef]

38. Zhang, X.; Wang, W.; Zhu, W.; Dong, J.; Cheng, Y.; Yin, Z.; Shen, F. Mechanisms and Functions of Long Non-Coding RNAs at Multiple Regulatory Levels. Int. J. Mol. Sci. 2019, 20, 5573. [CrossRef]

39. Prestayko, A.W.; D’aoust, J.; Issell, B.; Crooke, S. Cisplatin (cis-diamminedichloroplatinum II). Cancer Treat. Rev. 1979, 6, 17-39. [CrossRef]

40. Galluzzi, L.; Senovilla, L.; Vitale, I.; Michels, J.; Martins, I.; Kepp, O.; Castedo, M.; Kroemer, G. Molecular mechanisms of cisplatin resistance. Oncogene 2012, 31, 1869-1883. [CrossRef]

41. Hu, Y.; Zhu, Q.-N.; Deng, J.-L.; Li, Z.-X.; Wang, G.; Zhu, Y.-S. Emerging role of long non-coding RNAs in cisplatin resistance. OncoTargets Ther. 2018, 11, 3185. [CrossRef] [PubMed] 
42. Mylavarapu, S.; Das, A.; Roy, M. Role of BRCA mutations in the modulation of response to platinum therapy. Front. Oncol. 2018, 8, 16. [CrossRef] [PubMed]

43. Fink, D.; Nebel, S.; Aebi, S.; Zheng, H.; Cenni, B.; Nehmé, A.; Christen, R.D.; Howell, S.B. The role of DNA mismatch repair in platinum drug resistance. Cancer Res. 1996, 56, 4881-4886. [PubMed]

44. Asada, N.; Tsuchiya, H.; Tomita, K. De novo deletions of p53 gene and wild-type p53 correlate with acquired cisplatin-resistance in human osteosarcoma OST cell line. Anticancer Res. 1999, 19, 5131-5137.

45. Leong, C.-O.; Vidnovic, N.; DeYoung, M.P.; Sgroi, D.; Ellisen, L.W. The p63/p73 network mediates chemosensitivity to cisplatin in a biologically defined subset of primary breast cancers. J. Clin. Investig. 2007, 117, 1370-1380. [CrossRef]

46. Liu, R.; Zeng, Y.; Zhou, C.-F.; Wang, Y.; Li, X.; Liu, Z.-Q.; Chen, X.-P.; Zhang, W.; Zhou, H.-H. Long noncoding RNA expression signature to predict platinum-based chemotherapeutic sensitivity of ovarian cancer patients. Sci. Rep. 2017, 7, 1-10. [CrossRef] [PubMed]

47. Bai, L.; Wang, A.; Zhang, Y.; Xu, X.; Zhang, X. Knockdown of MALAT1 enhances chemosensitivity of ovarian cancer cells to cisplatin through inhibiting the Notch1 signaling pathway. Exp. Cell Res. 2018, 366, 161-171. [CrossRef]

48. Long, X.; Song, K.; Hu, H.; Tian, Q.; Wang, W.; Dong, Q.; Yin, X.; Di, W. Long non-coding RNA GAS5 inhibits DDP-resistance and tumor progression of epithelial ovarian cancer via GAS5-E2F4-PARP1-MAPK axis. J. Exp. Clin. 2019, 38, 345. [CrossRef]

49. Jiang, P.; Wu, X.; Wang, X.; Huang, W.; Feng, Q. NEAT1 upregulates EGCG-induced CTR1 to enhance cisplatin sensitivity in lung cancer cells. Oncotarget 2016, 7, 43337-43351. [CrossRef]

50. Zheng, Z.-G.; Xu, H.; Suo, S.-S.; Xu, X.-L.; Ni, M.-W.; Gu, L.-H.; Chen, W.; Wang, L.-Y.; Zhao, Y.; Tian, B. The essential role of $\mathrm{H} 19$ contributing to cisplatin resistance by regulating glutathione metabolism in high-grade serous ovarian cancer. Sci. Rep. 2016, 6, 26093. [CrossRef]

51. Wu, Y.; Zhou, Y.; He, J.; Sun, H.; Jin, Z. Long non-coding RNA H19 mediates ovarian cancer cell cisplatin-resistance and migration during EMT. Int. J. Clin. Exp. Pathol. 2019, 12, 2506. [PubMed]

52. Yu, Y.; Zhang, X.; Tian, H.; Zhang, Z.; Tian, Y. Knockdown of long non-coding RNA HOTAIR increases cisplatin sensitivity in ovarian cancer by inhibiting cisplatin-induced autophagy. J. Buon 2018, 23, 1396-1401. [PubMed]

53. Sun, M.Y.; Zhu, J.Y.; Zhang, C.Y.; Zhang, M.; Song, Y.N.; Rahman, K.; Zhang, L.J.; Zhang, H. Autophagy regulated by lncRNA HOTAIR contributes to the cisplatin-induced resistance in endometrial cancer cells. Biotechnol. Lett. 2017, 39, 1477-1484. [CrossRef] [PubMed]

54. Zhang, Y.; Ai, H.; Fan, X.; Chen, S.; Wang, Y.; Liu, L. Knockdown of long non-coding RNA HOTAIR reverses cisplatin resistance of ovarian cancer cells through inhibiting miR-138-5p-regulated EZH2 and SIRT1. Biol. Res. 2020, 53, 1-10. [CrossRef]

55. Li, J.; Yang, S.; Su, N.; Wang, Y.; Yu, J.; Qiu, H.; He, X. Overexpression of long non-coding RNA HOTAIR leads to chemoresistance by activating the $\mathrm{Wnt} / \beta$-catenin pathway in human ovarian cancer. Tumor Biol. 2016, 37, 2057-2065. [CrossRef]

56. Özeş, A.R.; Miller, D.F.; Özeş, O.N.; Fang, F.; Liu, Y.; Matei, D.; Huang, T.; Nephew, K.P. NF-kB-HOTAIR axis links DNA damage response, chemoresistance and cellular senescence in ovarian cancer. Oncogene 2016, 35, 5350-5361. [CrossRef]

57. Teschendorff, A.E.; Lee, S.H.; Jones, A.; Fiegl, H.; Kalwa, M.; Wagner, W.; Chindera, K.; Evans, I.; Dubeau, L.; Orjalo, A.; et al. HOTAIR and its surrogate DNA methylation signature indicate carboplatin resistance in ovarian cancer. Genome Med. 2015, 7, 108. [CrossRef]

58. Wang, H.; Fang, L.; Jiang, J.; Kuang, Y.; Wang, B.; Shang, X.; Han, P.; Li, Y.; Liu, M.; Zhang, Z. The cisplatin-induced lncRNA PANDAR dictates the chemoresistance of ovarian cancer via regulating SFRS2-mediated p53 phosphorylation. Cell Death Dis. 2018, 9, 1-15. [CrossRef]

59. Zhao, L.; Yang, J.; Liu, X.; Fu, X.; Ding, Y.; Wang, C. Overexpression of Long Noncoding RNA E2F-Mediated Cell Proliferation Enhancing Long Noncoding RNA Is Involved in the Development of Chemoresistance of Cancer Cells to Carboplatin in Ovarian Endometrioid Adenocarcinoma. Cancer Biother. Radiopharm. 2019, 34, 566-571. [CrossRef]

60. Liu, E.; Liu, Z.; Zhou, Y. Carboplatin-docetaxel-induced activity against ovarian cancer is dependent on up-regulated lncRNA PVT1. Int. J. Clin. Exp. Pathol. 2015, 8, 3803. 
61. Wang, D.-Y.; Li, N.; Cui, Y.-L. Long Non-coding RNA CCAT1 Sponges miR-454 to Promote Chemoresistance of Ovarian Cancer Cells to Cisplatin by Regulation of Surviving. J. Korean Cancer Assoc. 2020, 52, 798-814. [CrossRef] [PubMed]

62. Zou, H.; Li, H. Knockdown of long non-coding RNA LINC00152 increases cisplatin sensitivity in ovarian cancer cells. Exp. Ther. Med. 2019, 18, 4510-4516. [CrossRef] [PubMed]

63. Li, Z.; Niu, H.; Qin, Q.; Yang, S.; Wang, Q.; Yu, C.; Wei, Z.; Jin, Z.; Wang, X.; Yang, A. lncRNA UCA1 mediates resistance to cisplatin by regulating the miR-143/FOSL2-signaling pathway in ovarian cancer. Mol. Ther. Nucleic Acids 2019, 17, 92-101. [CrossRef] [PubMed]

64. Zhang, P.-F.; Wu, J.; Luo, J.-H.; Li, K.-S.; Wang, F.; Huang, W.; Wu, Y.; Gao, S.-P.; Zhang, X.-M.; Zhang, P.-N. SNHG22 overexpression indicates poor prognosis and induces chemotherapy resistance via the miR-2467/Gal-1 signaling pathway in epithelial ovarian carcinoma. Aging 2019, 11, 8204. [CrossRef]

65. Guo, J.; Pan, H. Long Noncoding RNA LINC01125 Enhances Cisplatin Sensitivity of Ovarian Cancer via miR-1972. Med Sci. Monit. Int. Med. J. Exp. Clin. Res. 2019, 25, 9844. [CrossRef]

66. Yan, H.; Xia, J.; Feng, F. Long non-coding RNA ENST00000457645 reverses cisplatin resistance in CP70 ovarian cancer cells. Genet. Mol. Res. 2017, 16, gmr16019411. [CrossRef]

67. Wu, D.I.; Wang, T.; Ren, C.; Liu, L.; Kong, D.; Jin, X.; Li, X.; Zhang, G. Downregulation of BC200 in ovarian cancer contributes to cancer cell proliferation and chemoresistance to carboplatin. Oncol. Lett. 2016, 11, 1189-1194. [CrossRef]

68. Shen, F.; Feng, L.; Zhou, J.; Zhang, H.; Xu, Y.; Jiang, R.; Zhang, H.; Chen, Y. Overexpression of CASC11 in ovarian squamous cell carcinoma mediates the development of cancer cell resistance to chemotherapy. Gene 2019, 710, 363-366. [CrossRef]

69. Qu, C.; Dai, C.; Guo, Y.; Qin, R.; Liu, J. Long noncoding RNA SNHG15 serves as an oncogene and predicts poor prognosis in epithelial ovarian cancer. OncoTargets Ther. 2019, 12, 101. [CrossRef]

70. Vera, O.; Rodriguez-Antolin, C.; De Castro, J.; Karreth, F.A.; Sellers, T.A.; Ibanez de Caceres, I. An epigenomic approach to identifying differential overlapping and cis-acting lncRNAs in cisplatin-resistant cancer cells. Epigenetics 2018, 13, 251-263. [CrossRef]

71. Ishida, S.; Lee, J.; Thiele, D.J.; Herskowitz, I. Uptake of the anticancer drug cisplatin mediated by the copper transporter Ctr1 in yeast and mammals. Proc. Natl. Acad. Sci. USA 2002, 99, 14298-14302. [CrossRef] [PubMed]

72. Katano, K.; Kondo, A.; Safaei, R.; Holzer, A.; Samimi, G.; Mishima, M.; Kuo, Y.-M.; Rochdi, M.; Howell, S.B. Acquisition of resistance to cisplatin is accompanied by changes in the cellular pharmacology of copper. Cancer Res. 2002, 62, 6559-6565. [PubMed]

73. Askarian-Amiri, M.E.; Crawford, J.; French, J.D.; Smart, C.E.; Smith, M.A.; Clark, M.B.; Ru, K.; Mercer, T.R.; Thompson, E.R.; Lakhani, S.R. SNORD-host RNA Zfas1 is a regulator of mammary development and a potential marker for breast cancer. RNA 2011, 17, 878-891. [CrossRef] [PubMed]

74. Lai, Y.-H.; Kuo, C.; Kuo, M.T.; Chen, H.H. Modulating chemosensitivity of tumors to platinum-based antitumor drugs by transcriptional regulation of copper homeostasis. Int. J. Mol. Sci. 2018, 19, 1486. [CrossRef] [PubMed]

75. Olofsson, B.A.; Kelly, C.M.; Kim, J.; Hornsby, S.M.; Azizkhan-Clifford, J. Phosphorylation of Sp1 in response to DNA damage by ataxia telangiectasia-mutated kinase. Mol. Cancer Res. 2007, 5, 1319-1330. [CrossRef]

76. Ji, P.; Diederichs, S.; Wang, W.; Böing, S.; Metzger, R.; Schneider, P.M.; Tidow, N.; Brandt, B.; Buerger, H.; Bulk, E. MALAT-1, a novel noncoding RNA, and thymosin $\beta 4$ predict metastasis and survival in early-stage non-small cell lung cancer. Oncogene 2003, 22, 8031-8041. [CrossRef]

77. Shi, X.; Sun, M.; Liu, H.; Yao, Y.; Song, Y. Long non-coding RNAs: A new frontier in the study of human diseases. Cancer Lett. 2013, 339, 159-166. [CrossRef]

78. Siddik, Z.H. Cisplatin: Mode of cytotoxic action and molecular basis of resistance. Oncogene 2003, 22, 7265-7279. [CrossRef]

79. Dabrowiak, J.C.; Goodisman, J.; Souid, A.-K. Kinetic study of the reaction of cisplatin with thiols. Drug Metab. Dispos. 2002, 30, 1378-1384. [CrossRef] [PubMed]

80. Jamali, B.; Nakhjavani, M.; Hosseinzadeh, L.; Amidi, S.; Nikounezhad, N.; Shirazi, F.H. Intracellular GSH alterations and its relationship to level of resistance following exposure to cisplatin in cancer cells. Iran. J. Pharm. Sci. 2015, 14, 513. 
81. Cao, T.; Jiang, Y.; Wang, Z.; Zhang, N.; Al-Hendy, A.; Mamillapalli, R.; Kallen, A.N.; Kodaman, P.; Taylor, H.S.; Li, D. H19 lncRNA identified as a master regulator of genes that drive uterine leiomyomas. Oncogene 2019, 38, 5356-5366. [CrossRef]

82. Wang, Q.; Cheng, N.; Li, X.; Pan, H.; Li, C.; Ren, S.; Su, C.; Cai, W.; Zhao, C.; Zhang, L. Correlation of long non-coding RNA H19 expression with cisplatin-resistance and clinical outcome in lung adenocarcinoma. Oncotarget 2017, 8, 2558. [CrossRef] [PubMed]

83. Wei, J.; Gan, Y.; Peng, D.; Jiang, X.; Kitazawa, R.; Xiang, Y.; Dai, Y.; Tang, Y.; Yang, J. Long non-coding RNA H19 promotes TDRG1 expression and cisplatin resistance by sequestering miRNA-106b-5p in seminoma. Cancer Med. 2018, 7, 6247-6257. [CrossRef] [PubMed]

84. Meijer, C.; Mulder, N.H.; Timmer-Bosscha, H.; Sluiter, W.J.; Meersma, G.J.; De Vries, E.G. Relationship of cellular glutathione to the cytotoxicity and resistance of seven platinum compounds. Cancer Res. 1992, 52, 6885-6889.

85. Klionsky, D.J. Autophagy: From phenomenology to molecular understanding in less than a decade. Nat. Rev. Mol. Cell Biol. 2007, 8, 931-937. [CrossRef]

86. Ren, J.-H.; He, W.-S.; Nong, L.; Zhu, Q.-Y.; Hu, K.; Zhang, R.-G.; Huang, L.-L.; Zhu, F.; Wu, G. Acquired cisplatin resistance in human lung adenocarcinoma cells is associated with enhanced autophagy. Cancer Biother. Radiopharm. 2010, 25, 75-80. [CrossRef]

87. Hu, Z.; Cai, M.; Zhang, Y.; Tao, L.; Guo, R. miR-29c-3p inhibits autophagy and cisplatin resistance in ovarian cancer by regulating FOXP1/ATG14 pathway. Cell Cycle 2020, 19, 193-206. [CrossRef] [PubMed]

88. Yamaguchi, M.; Satoo, K.; Suzuki, H.; Fujioka, Y.; Ohsumi, Y.; Inagaki, F.; Noda, N.N. Atg7 Activates an Autophagy-Essential Ubiquitin-like Protein Atg8 through Multi-Step Recognition. J. Mol. Biol. 2018, 430, 249-257. [CrossRef]

89. Brown, C.J.; Ballabio, A.; Rupert, J.L.; Lafreniere, R.G.; Grompe, M.; Tonlorenzi, R.; Willard, H.F. A gene from the region of the human $\mathrm{X}$ inactivation centre is expressed exclusively from the inactive $\mathrm{X}$ chromosome. Nature 1991, 349, 38-44. [CrossRef]

90. Sun, W.; Zu, Y.; Fu, X.; Deng, Y. Knockdown of lncRNA-XIST enhances the chemosensitivity of NSCLC cells via suppression of autophagy. Oncol. Rep. 2017, 38, 3347-3354. [CrossRef]

91. Dongre, A.; Weinberg, R.A. New insights into the mechanisms of epithelial-mesenchymal transition and implications for cancer. Nat. Rev. Mol. Cell Biol. 2019, 20, 69-84. [CrossRef] [PubMed]

92. Singh, A.; Settleman, J. EMT, cancer stem cells and drug resistance: An emerging axis of evil in the war on cancer. Oncogene 2010, 29, 4741-4751. [CrossRef]

93. Cano, A.; Pérez-Moreno, M.A.; Rodrigo, I.; Locascio, A.; Blanco, M.J.; Del Barrio, M.G.; Portillo, F.; Nieto, M.A. The transcription factor snail controls epithelial-mesenchymal transitions by repressing E-cadherin expression. Nat. Cell Biol. 2000, 2, 76-83. [CrossRef] [PubMed]

94. Herranz, N.; Pasini, D.; Díaz, V.M.; Francí, C.; Gutierrez, A.; Dave, N.; Escrivà, M.; Hernandez-Muñoz, I.; Di Croce, L.; Helin, K. Polycomb complex 2 is required for E-cadherin repression by the Snail1 transcription factor. Mol. Cell. Biol. 2008, 28, 4772-4781. [CrossRef] [PubMed]

95. Zhang, W.; Shi, X.; Peng, Y.; Wu, M.; Zhang, P.; Xie, R.; Wu, Y.; Yan, Q.; Liu, S.; Wang, J. HIF-1 $\alpha$ Promotes Epithelial-Mesenchymal Transition and Metastasis through Direct Regulation of ZEB1 in Colorectal Cancer. PLoS ONE 2015, 10, e0129603. [CrossRef]

96. Jackson, S.P.; Bartek, J. The DNA-damage response in human biology and disease. Nature 2009, 461, 1071-1078. [CrossRef]

97. Janssens, S.; Tinel, A.; Lippens, S.; Tschopp, J. PIDD mediates NF-kB activation in response to DNA damage. Cell 2005, 123, 1079-1092. [CrossRef]

98. Righetti, S.C.; Della Torre, G.; Pilotti, S.; Ménard, S.; Ottone, F.; Colnaghi, M.I.; Pierotti, M.A.; Lavarino, C.; Cornarotti, M.; Oriana, S. A comparative study of p53 gene mutations, protein accumulation, and response to cisplatin-based chemotherapy in advanced ovarian carcinoma. Cancer Res. 1996, 56, 689-693.

99. Schneider, C.; King, R.M.; Philipson, L. Genes specifically expressed at growth arrest of mammalian cells. Cell 1988, 54, 787-793. [CrossRef]

100. Dong, S.; Qu, X.; Li, W.; Zhong, X.; Li, P.; Yang, S.; Chen, X.; Shao, M.; Zhang, L. The long non-coding RNA, GAS5, enhances gefitinib-induced cell death in innate EGFR tyrosine kinase inhibitor-resistant lung adenocarcinoma cells with wide-type EGFR via downregulation of the IGF-1R expression. J. Hematol. Oncol. 2015, 8, 43. [CrossRef] 
101. Yang, W.; Hong, L.; Xu, X.; Wang, Q.; Huang, J.; Jiang, L. LncRNA GAS5 suppresses the tumorigenesis of cervical cancer by downregulating miR-196a and miR-205. Tumor Biol. 2017, 39. [CrossRef] [PubMed]

102. Tao, R.; Hu, S.; Wang, S.; Zhou, X.; Zhang, Q.; Wang, C.; Zhao, X.; Zhou, W.; Zhang, S.; Li, C. Association between indel polymorphism in the promoter region of lncRNA GAS5 and the risk of hepatocellular carcinoma. Carcinogenesis 2015, 36, 1136-1143. [CrossRef]

103. Pickard, M.R.; Williams, G.T. Regulation of apoptosis by long non-coding RNA GAS5 in breast cancer cells: Implications for chemotherapy. Breast Cancer Res. Tr. 2014, 145, 359-370. [CrossRef]

104. Jain, P.G.; Patel, B.D. Medicinal chemistry approaches of poly ADP-Ribose polymerase 1 (PARP1) inhibitors as anticancer agents-A recent update. Eur. J. Med. Chem. 2019, 165, 198-215. [CrossRef]

105. Fulda, S.; Debatin, K.-M. Extrinsic versus intrinsic apoptosis pathways in anticancer chemotherapy. Oncogene 2006, 25, 4798-4811. [CrossRef]

106. Youle, R.J.; Strasser, A. The BCL-2 protein family: Opposing activities that mediate cell death. Nat. Rev. Mol. Cell Biol. 2008, 9, 47-59. [CrossRef] [PubMed]

107. Hung, T.; Wang, Y.; Lin, M.F.; Koegel, A.K.; Kotake, Y.; Grant, G.D.; Horlings, H.M.; Shah, N.; Umbricht, C.; Wang, P. Extensive and coordinated transcription of noncoding RNAs within cell-cycle promoters. Nat. Genet. 2011, 43, 621. [CrossRef] [PubMed]

108. Kędzierska, H.; Piekiełko-Witkowska, A. Splicing factors of SR and hnRNP families as regulators of apoptosis in cancer. Cancer Lett. 2017, 396, 53-65. [CrossRef]

109. Xiao, R.; Sun, Y.; Ding, J.-H.; Lin, S.; Rose, D.W.; Rosenfeld, M.G.; Fu, X.-D.; Li, X. Splicing regulator SC35 is essential for genomic stability and cell proliferation during mammalian organogenesis. Mol. Cell. Biol. 2007, 27, 5393-5402. [CrossRef]

110. Park, S.M.; Choi, E.Y.; Bae, D.H.; Sohn, H.A.; Kim, S.Y.; Kim, Y.J. The LncRNA EPEL Promotes Lung Cancer Cell Proliferation Through E2F Target Activation. Cell. Physiol. Biochem. 2018, 45, 1270-1283. [CrossRef]

111. Bao, W.; Fu, H.-J.; Jia, L.-T.; Zhang, Y.; Li, W.; Jin, B.-Q.; Yao, L.-B.; Chen, S.-Y.; Yang, A.-G. HER2-mediated upregulation of MMP-1 is involved in gastric cancer cell invasion. Arch. Biochem. Biophys. 2010, 499, 49-55. [CrossRef] [PubMed]

112. Würtz, S.Ø.; Møller, S.; Mouridsen, H.; Hertel, P.B.; Friis, E.; Brünner, N. Plasma and serum levels of tissue inhibitor of metalloproteinases-1 are associated with prognosis in node-negative breast cancer: A prospective study. Mol. Cell. Proteom. 2008, 7, 424-430. [CrossRef]

113. Nissan, A.; Stojadinovic, A.; Mitrani-Rosenbaum, S.; Halle, D.; Grinbaum, R.; Roistacher, M.; Bochem, A.; Dayanc, B.E.; Ritter, G.; Gomceli, I. Colon cancer associated transcript-1: A novel RNA expressed in malignant and pre-malignant human tissues. Int. J. Cancer. 2012, 130, 1598-1606. [CrossRef]

114. Deng, L.; Yang, S.-B.; Xu, F.-F.; Zhang, J.-H. Long noncoding RNA CCAT1 promotes hepatocellular carcinoma progression by functioning as let-7 sponge. J. Exp. Clin. 2015, 34, 18. [CrossRef] [PubMed]

115. Ma, M.; Chu, B.; Zhang, Y.; Weng, M.; Qin, Y.; Gong, W.; Quan, Z. Long non-coding RNA CCAT1 promotes gallbladder cancer development via negative modulation of miRNA-218-5p. Cell Death Dis. 2015, 6, e1583. [CrossRef] [PubMed]

116. Liu, E.; Liu, Z.; Zhou, Y.; Mi, R.; Wang, D. Overexpression of long non-coding RNA PVT1 in ovarian cancer cells promotes cisplatin resistance by regulating apoptotic pathways. Int. J. Clin. Exp. Med. 2015, 8, 20565-20572.

117. Xiao, J.-N.; Yan, T.-H.; Yu, R.-M.; Gao, Y.; Zeng, W.-L.; Lu, S.-W.; Que, H.-X.; Liu, Z.-P.; Jiang, J.-H. Long non-coding RNA UCA1 regulates the expression of Snail2 by miR-203 to promote hepatocellular carcinoma progression. J. Cancer Res. Clin. 2017, 143, 981-990. [CrossRef] [PubMed]

118. Bian, Z.; Jin, L.; Zhang, J.; Yin, Y.; Quan, C.; Hu, Y.; Feng, Y.; Liu, H.; Fei, B.; Mao, Y. LncRNA—UCA1 enhances cell proliferation and 5-fluorouracil resistance in colorectal cancer by inhibiting miR-204-5p. Sci. Rep. 2016, 6, 23892. [CrossRef]

119. Zhou, Y.; Meng, X.; Chen, S.; Li, W.; Li, D.; Singer, R.; Gu, W. IMP1 regulates UCA1-mediated cell invasion through facilitating UCA1 decay and decreasing the sponge effect of UCA1 for miR-122-5p. Breast Cancer Res. 2018, 20, 32. [CrossRef]

120. Zhang, L.; Cao, X.; Zhang, L.; Zhang, X.; Sheng, H.; Tao, K. UCA1 overexpression predicts clinical outcome of patients with ovarian cancer receiving adjuvant chemotherapy. Cancer Chemoth. Pharm. 2016, 77, 629-634. [CrossRef] 
121. Wang, X.-S.; Zhang, Z.; Wang, H.-C.; Cai, J.-L.; Xu, Q.-W.; Li, M.-Q.; Chen, Y.-C.; Qian, X.-P.; Lu, T.-J.; Yu, L.-Z. Rapid identification of UCA1 as a very sensitive and specific unique marker for human bladder carcinoma. Clin. Cancer Res. 2006, 12, 4851-4858. [CrossRef] [PubMed]

122. Tulchinsky, E. Fos family members: Regulation, structure and role in oncogenic transformation. Histol. Histopathol. 2000, 15, 921-928.

123. Li, S.; Fang, X.-D.; Wang, X.-Y.; Fei, B.-Y. Fos-like antigen 2 (FOSL2) promotes metastasis in colon cancer. Exp. Cell Res. 2018, 373, 57-61. [CrossRef] [PubMed]

124. Yin, J.; Hu, W.; Fu, W.; Dai, L.; Jiang, Z.; Zhong, S.; Deng, B.; Zhao, J. HGF/MET Regulated Epithelial-Mesenchymal Transitions and Metastasis by FOSL2 in Non-Small Cell Lung Cancer. OncoTargets Ther. 2019, 12, 9227. [CrossRef] [PubMed]

125. Wang, C.; Qi, S.; Xie, C.; Li, C.; Wang, P.; Liu, D. Upregulation of long non-coding RNA XIST has anticancer effects on epithelial ovarian cancer cells through inverse downregulation of hsa-miR-214-3p. Gynecol. Oncol. 2018, 29, e99. [CrossRef]

126. Samson, J.; Cronin, S.; Dean, K. BC200 (BCYRN1)-The shortest, long, non-coding RNA associated with cancer. Noncoding RNA Res. 2018, 3, 131-143. [CrossRef]

127. Rao, S.; Orr, G.A.; Chaudhary, A.G.; Kingston, D.G.; Horwitz, S.B. Characterization of the Taxol Binding Site on the Microtubule. 2-(m-Azidobenzoyl)taxol Photolabels a Peptide (Amino Acids 217-231) of Beta-Tubulin. J. Biol. Chem. 1995, 270, 20235-20238. [CrossRef]

128. Rowinsky, E.K.; Donehower, R.C. Paclitaxel (taxol). N. Engl. J. Med. 1995, 332, 1004-1014. [CrossRef]

129. Ranganathan, S.; Benetatos, C.; Colarusso, P.; Dexter, D.; Hudes, G. Altered $\beta$-tubulin isotype expression in paclitaxel-resistant human prostate carcinoma cells. Br. J. Cancer 1998, 77, 562-566. [CrossRef]

130. Rao, R.; Markovic, S.N.; Anderson, P. Aerosol therapy for malignancy involving the lungs. Curr. Cancer Drug Targets 2003, 3, 239-250. [CrossRef]

131. Wang, J.; Ye, C.; Liu, J.; Hu, Y. UCA1 confers paclitaxel resistance to ovarian cancer through miR-129/ABCB1 axis. Biochem. Biophys. Res. Commun. 2018, 501, 1034-1040. [CrossRef] [PubMed]

132. Li, Z.; Wang, X.; Dang, Y.; Zhu, X.; Zhang, Y.; Cai, B.; Zheng, L. Long non-coding RNA UCA1 promotes the progression of paclitaxel resistance in ovarian cancer by regulating the miR-654-5p/SIK2 axis. Eur. Rev. Med. Pharmacol. Sci. 2020, 24, 591-603.

133. Shi, C.; Wang, M. LINC01118 modulates paclitaxel resistance of epithelial ovarian cancer by regulating miR-134/ABCC1. Med. Sci. Monit. 2018, 24, 8831. [CrossRef] [PubMed]

134. An, J.; Lv, W.; Zhang, Y. LncRNA NEAT1 contributes to paclitaxel resistance of ovarian cancer cells by regulating ZEB1 expression via miR-194. OncoTargets Ther. 2017, 10, 5377. [CrossRef] [PubMed]

135. Dong, P.; Xiong, Y.; Yue, J.; Xu, D.; Ihira, K.; Konno, Y.; Kobayashi, N.; Todo, Y.; Watari, H. Long noncoding RNA NEAT1 drives aggressive endometrial cancer progression via miR-361-regulated networks involving STAT3 and tumor microenvironment-related genes. J. Exp. Clin. Cancer Res. 2019, 38, 295. [CrossRef] [PubMed]

136. Lin, H.; Shen, L.; Lin, Q.; Dong, C.; Maswela, B.; Illahi, G.S.; Wu, X. SNHG5 enhances Paclitaxel sensitivity of ovarian cancer cells through sponging miR-23a. Biomed. Pharmacother. 2020, 123, 109711. [CrossRef]

137. Zhao, H.; Wang, A.; Zhang, Z. LncRNA SDHAP1 confers paclitaxel resistance of ovarian cancer by regulating EIF4G2 expression via miR-4465. J. Biochem. 2020, 168. [CrossRef]

138. Guo, J.-L.; Tang, T.; Li, J.-H.; Yang, Y.-H.; Zhang, L.; Quan, Y. LncRNA HEIH Enhances Paclitaxel-Tolerance of Endometrial Cancer Cells via Activation of MAPK Signaling Pathway. Pathol. Oncol. Res. 2019, 1-10. [CrossRef]

139. Liu, S.; Zou, B.; Tian, T.; Luo, X.; Mao, B.; Zhang, X.; Lei, H. Overexpression of the lncRNA FER1L4 inhibits paclitaxel tolerance of ovarian cancer cells via the regulation of the MAPK signaling pathway. J. Cell. Biochem. 2019, 120, 7581-7589. [CrossRef]

140. Zhang, C.; Wang, M.; Shi, C.; Shi, F.; Pei, C. Long non-coding RNA Linc00312 modulates the sensitivity of ovarian cancer to cisplatin via the Bcl-2/Caspase-3 signaling pathway. Biosci. Trends 2018, 12, 309-316. [CrossRef]

141. Shang, C.; Ao, C.N.; Cheong, C.C.; Meng, L. Long non-coding RNA CDKN2B antisense RNA 1 gene contributes to paclitaxel resistance in endometrial carcinoma. Front. Oncol. 2019, 9, 27. [CrossRef] [PubMed] 
142. Zhang, M.; Liu, S.; Fu, C.; Wang, X.; Zhang, M.; Liu, G.; Dai, C.; Gong, Z.; Xu, H.; Fu, Z. LncRNA KB-1471A8. 2 Overexpression Suppresses Cell Proliferation and Migration and Antagonizes the Paclitaxel Resistance of Ovarian Cancer Cells. Cancer Biother. Radiopharm. 2019, 34, 316-324. [CrossRef] [PubMed]

143. Xu, J.; Wu, J.; Fu, C.; Teng, F.; Liu, S.; Dai, C.; Shen, R.; Jia, X. Multidrug resistant lncRNA profile in chemotherapeutic sensitive and resistant ovarian cancer cells. J. Cell. Physiol. 2018, 233, 5034-5043. [CrossRef]

144. Yu, X.; Li, Z.; Zheng, H.; Chan, M.T.; Wu, W.K.K. NEAT 1: A novel cancer-related long non-coding RNA. Cell Prolif. 2017, 50, e12329. [CrossRef] [PubMed]

145. McCain, J. The MAPK (ERK) pathway: Investigational combinations for the treatment of BRAF-mutated metastatic melanoma. Pharm. Ther. 2013, 38, 96.

146. Yang, F.; Xu, D.; Yuan, S.X.; Zhu, N.; Zhou, W.P.; Yang, G.S.; Wang, Y.Z.; Shang, J.L.; Gao, C.f.; Zhang, F.R.; et al. Long noncoding RNA high expression in hepatocellular carcinoma facilitates tumor growth through enhancer of zeste homolog 2 in humans. Hepatology 2011, 54, 1679-1689. [CrossRef] [PubMed]

147. Ming, M.; He, Y.-Y. PTEN in DNA damage repair. Cancer Lett. 2012, 319, 125-129. [CrossRef] [PubMed]

148. Chen, Z.X.; Chen, C.P.; Zhang, N.; Wang, T.X. Low-expression of lncRNA FER1L4 might be a prognostic marker in osteosarcoma. Eur. Rev. Med. Pharmacol. Sci. 2018, 22, 2310-2314.

149. Ma, W.; Zhang, C.Q.; Li, H.L.; Gu, J.; Miao, G.Y.; Cai, H.Y.; Wang, J.K.; Zhang, L.J.; Song, Y.M.; Tian, Y.H.; et al. LncRNA FER1L4 suppressed cancer cell growth and invasion in esophageal squamous cell carcinoma. Eur. Rev. Med. Pharmacol. Sci. 2018, 22, 2638-2645.

150. Qiao, Q.; Li, H. LncRNA FER1L4 suppresses cancer cell proliferation and cycle by regulating PTEN expression in endometrial carcinoma. Biochem. Biophys. Res. Commun. 2016, 478, 507-512. [CrossRef]

151. Wang, X.; Dong, K.; Jin, Q.; Ma, Y.; Yin, S.; Wang, S. Upregulation of lncRNA FER1L4 suppresses the proliferation and migration of the hepatocellular carcinoma via regulating PI3K/AKT signal pathway. J. Cell. Biochem. 2019, 120, 6781-6788. [CrossRef]

152. Xia, T.; Liao, Q.; Jiang, X.; Shao, Y.; Xiao, B.; Xi, Y.; Guo, J. Long noncoding RNA associated-competing endogenous RNAs in gastric cancer. Sci. Rep. 2014, 4, 1-7. [CrossRef] [PubMed]

153. Ma, J.; Li, T.; Han, X.; Yuan, H. Knockdown of LncRNA ANRIL suppresses cell proliferation, metastasis, and invasion via regulating miR-122-5p expression in hepatocellular carcinoma. J. Cancer Res. Clin. Oncol. 2018, 144, 205-214. [CrossRef] [PubMed]

154. Zhang, J.-J.; Wang, D.-D.; Du, C.-X.; Wang, Y. Long noncoding RNA ANRIL promotes cervical cancer development by acting as a sponge of miR-186. Oncol. Res. 2018, 26, 345-352. [CrossRef] [PubMed]

155. Xu, S.-T.; Xu, J.-H.; Zheng, Z.-R.; Zhao, Q.-Q.; Zeng, X.-S.; Cheng, S.-X.; Liang, Y.-H.; Hu, Q.-F. Long non-coding RNA ANRIL promotes carcinogenesis via sponging miR-199a in triple-negative breast cancer. Biomed. Pharmacother. 2017, 96, 14-21. [CrossRef] [PubMed]

156. Zhao, B.; Lu, Y.-L.; Yang, Y.; Hu, L.-B.; Bai, Y.; Li, R.-Q.; Zhang, G.-Y.; Li, J.; Bi, C.-W.; Yang, L.-B. Overexpression of lncRNA ANRIL promoted the proliferation and migration of prostate cancer cells via regulating let-7a/TGF- $31 / S m a d$ signaling pathway. Cancer Biomark. 2018, 21, 613-620. [CrossRef]

157. Zhong, L.; Sun, S.; Shi, J.; Cao, F.; Han, X.; Chen, Z. MicroRNA-125a-5p plays a role as a tumor suppressor in lung carcinoma cells by directly targeting STAT3. Tumor Biol. 2017, 39. [CrossRef]

158. Tong, Z.; Liu, N.; Lin, L.; Guo, X.; Yang, D.; Zhang, Q. miR-125a-5p inhibits cell proliferation and induces apoptosis in colon cancer via targeting BCL2, BCL2L12 and MCL1. Biomed. Pharmacother. 2015, 75, 129-136. [CrossRef]

159. Pacilli, A.; Ceccarelli, C.; Treré, D.; Montanaro, L. SnoRNA U50 Levels Are Regulated by Cell Proliferation and rRNA Transcription. Int. J. Mol. Sci. 2013, 14, 14923-14935. [CrossRef]

160. Zhuang, R.-J.; Bai, X.-X.; Liu, W. MicroRNA-23a depletion promotes apoptosis of ovarian cancer stem cell and inhibits cell migration by targeting DLG2. Cancer Biol. Ther. 2019, 20, 897-911. [CrossRef]

161. Xu, F.; Li, Q.; Wang, Z.; Cao, X. Sinomenine inhibits proliferation, migration, invasion and promotes apoptosis of prostate cancer cells by regulation of miR-23a. Biomed. Pharmacother. 2019, 112, 108592. [CrossRef] [PubMed]

162. Majem, B.; Parrilla, A.; Jiménez, C.; Suárez-Cabrera, L.; Barber, M.; Marín, A.; Castellví, J.; Tamayo, G.; Moreno-Bueno, G.; Ponce, J. MicroRNA-654-5p suppresses ovarian cancer development impacting on MYC, WNT and AKT pathways. Oncogene 2019, 38, 6035-6050. [CrossRef] [PubMed] 
163. Du, W.-Q.; Zheng, J.-N.; Pei, D.-S. The diverse oncogenic and tumor suppressor roles of salt-inducible kinase (SIK) in cancer. Expert Opin. Ther. Targets 2016, 20, 477-485. [CrossRef] [PubMed]

164. Miranda, F.; Mannion, D.; Liu, S.; Zheng, Y.; Mangala, L.S.; Redondo, C.; Herrero-Gonzalez, S.; Xu, R.; Taylor, C.; Chedom, D.F. Salt-inducible kinase 2 couples ovarian cancer cell metabolism with survival at the adipocyte-rich metastatic niche. Cancer Cell 2016, 30, 273-289. [CrossRef]

165. Wang, L.; Hu, Y.; Xiang, X.; Qu, K.; Teng, Y. Identification of long non-coding RNA signature for paclitaxel-resistant patients with advanced ovarian cancer. Oncotarget 2017, 8, 64191. [CrossRef]

166. Huang, K.-C.; Rao, P.H.; Lau, C.C.; Heard, E.; Ng, S.-K.; Brown, C.; Mok, S.C.; Berkowitz, R.S.; Ng, S.-W. Relationship of XIST Expression and Responses of Ovarian Cancer to Chemotherapy 1. Mol. Cancer Ther. 2002, 1, 769-776.

167. Arun, G.; Diermeier, S.D.; Spector, D.L. Therapeutic targeting of long non-coding RNAs in cancer. Trends Mol. Med. 2018, 24, 257-277. [CrossRef]

168. Hannon, G.J.; Rossi, J.J. Unlocking the potential of the human genome with RNA interference. Nature 2004, 431, 371-378. [CrossRef]

169. Morrissey, D.V.; Lockridge, J.A.; Shaw, L.; Blanchard, K.; Jensen, K.; Breen, W.; Hartsough, K.; Machemer, L.; Radka, S.; Jadhav, V.; et al. Potent and persistent in vivo anti-HBV activity of chemically modified siRNAs. Nat. Biotechnol. 2005, 23, 1002-1007. [CrossRef]

170. Yoo, B.H.; Bochkareva, E.; Bochkarev, A.; Mou, T.C.; Gray, D.M. 2'-O-methyl-modified phosphorothioate antisense oligonucleotides have reduced non-specific effects in vitro. Nucleic Acids Res. 2004, 32, 2008-2016. [CrossRef]

171. Crooke, S.T. Molecular Mechanisms of Antisense Oligonucleotides. Nucleic Acid Ther. 2017, $27,70-77$. [CrossRef] [PubMed]

172. Bennett, C.F.; Baker, B.F.; Pham, N.; Swayze, E.; Geary, R.S. Pharmacology of antisense drugs. Annu. Rev. Pharmacol. Toxicol. 2017, 57, 81-105. [CrossRef] [PubMed]

173. Pickar-Oliver, A.; Gersbach, C.A. The next generation of CRISPR-Cas technologies and applications. Nat. Rev. Mol. Cell Biol. 2019, 20, 490-507. [CrossRef]

174. Gilbert, L.A.; Horlbeck, M.A.; Adamson, B.; Villalta, J.E.; Chen, Y.; Whitehead, E.H.; Guimaraes, C.; Panning, B.; Ploegh, H.L.; Bassik, M.C.; et al. Genome-Scale CRISPR-Mediated Control of Gene Repression and Activation. Cell 2014, 159, 647-661. [CrossRef] [PubMed]

175. Thakore, P.I.; D'ippolito, A.M.; Song, L.; Safi, A.; Shivakumar, N.K.; Kabadi, A.M.; Reddy, T.E.; Crawford, G.E.; Gersbach, C.A. Highly specific epigenome editing by CRISPR-Cas9 repressors for silencing of distal regulatory elements. Nat. Methods 2015, 12, 1143. [CrossRef]

176. Abudayyeh, O.O.; Gootenberg, J.S.; Essletzbichler, P.; Han, S.; Joung, J.; Belanto, J.J.; Verdine, V.; Cox, D.B.T.; Kellner, M.J.; Regev, A.; et al. RNA targeting with CRISPR-Cas13. Nature 2017, 550, 280-284. [CrossRef]

177. Wilusz, J.E.; JnBaptiste, C.K.; Lu, L.Y.; Kuhn, C.-D.; Joshua-Tor, L.; Sharp, P.A. A triple helix stabilizes the $3^{\prime}$ ends of long noncoding RNAs that lack poly (A) tails. Genes Dev. 2012, 26, 2392-2407. [CrossRef]

178. Katayama, S.; Tomaru, Y.; Kasukawa, T.; Waki, K.; Nakanishi, M.; Nakamura, M.; Nishida, H.; Yap, C.; Suzuki, M.; Kawai, J. Antisense transcription in the mammalian transcriptome. Science 2005, 309, 1564-1566.

179. Modarresi, F.; Faghihi, M.A.; Lopez-Toledano, M.A.; Fatemi, R.P.; Magistri, M.; Brothers, S.P.; Van Der Brug, M.P.; Wahlestedt, C. Inhibition of natural antisense transcripts in vivo results in gene-specific transcriptional upregulation. Nat. Biotechnol. 2012, 30, 453. [CrossRef]

180. Yap, K.L.; Li, S.; Muñoz-Cabello, A.M.; Raguz, S.; Zeng, L.; Mujtaba, S.; Gil, J.; Walsh, M.J.; Zhou, M.-M. Molecular interplay of the noncoding RNA ANRIL and methylated histone H3 lysine 27 by polycomb CBX7 in transcriptional silencing of INK4a. Mol. Cell 2010, 38, 662-674. [CrossRef]

181. Dimitrova, N.; Zamudio, J.R.; Jong, R.M.; Soukup, D.; Resnick, R.; Sarma, K.; Ward, A.J.; Raj, A.; Lee, J.T.; Sharp, P.A. LincRNA-p21 activates p21 in cis to promote Polycomb target gene expression and to enforce the G1/S checkpoint. Mol. Cell 2014, 54, 777-790. [CrossRef] [PubMed]

182. Redis, R.S.; Vela, L.E.; Lu, W.; Ferreira de Oliveira, J.; Ivan, C.; Rodriguez-Aguayo, C.; Adamoski, D.; Pasculli, B.; Taguchi, A.; Chen, Y.; et al. Allele-specific reprogramming of cancer metabolism by the long non-coding RNA ccat2. Mol. Cell 2016, 61, 520-534. [CrossRef]

183. Pichler, M.; Rodriguez-Aguayo, C.; Nam, S.Y.; Dragomir, M.P.; Bayraktar, R.; Anfossi, S.; Knutsen, E.; Ivan, C.; Fuentes-Mattei, E.; Lee, S.K.; et al. Therapeutic potential of flanc, a novel primate-specific long non-coding RNA in colorectal cancer. Gut 2020. [CrossRef] [PubMed] 
184. Rigoutsos, I.; Lee, S.K.; Nam, S.Y.; Anfossi, S.; Pasculli, B.; Pichler, M.; Jing, Y.; Rodriguez-Aguayo, C.; Telonis, A.G.; Rossi, S.; et al. N-blr, a primate-specific non-coding transcript leads to colorectal cancer invasion and migration. Genome Biol. 2017, 18, 98. [CrossRef] [PubMed]

185. Salamini-Montemurri, M.; Lamas-Maceiras, M.; Barreiro-Alonso, A.; Vizoso-Vázquez, Á.; Rodríguez-Belmonte, E.; Quindós-Varela, M.; Cerdán, M.E. The challenges and opportunities of lncRNAs in ovarian cancer research and clinical use. Cancers 2020, 12, 1020. [CrossRef]

186. Pei, C.L.; Fei, K.L.; Yuan, X.Y.; Gong, X.J. LncRNA dancr aggravates the progression of ovarian cancer by downregulating upf1. Eur. Rev. Med. Pharmacol. Sci. 2019, 23, 10657-10663.

187. Yang, M.; Zhai, Z.; Guo, S.; Li, X.; Zhu, Y.; Wang, Y. Long non-coding RNA flj33360 participates in ovarian cancer progression by sponging mir-30b-3p. Onco Targets Ther. 2019, 12, 4469-4480. [CrossRef]

188. Ning, L.; Hu, Y.C.; Wang, S.; Lang, J.H. Altered long noncoding rnas and survival outcomes in ovarian cancer: A systematic review and meta-analysis (prisma compliant). Medicine 2018, 97, e11481. [CrossRef]

189. Luo, P.; Liu, X.F.; Wang, Y.C.; Li, N.D.; Liao, S.J.; Yu, M.X.; Liang, C.Z.; Tu, J.C. Prognostic value of abnormally expressed lncRNAs in ovarian carcinoma: A systematic review and meta-analysis. Oncotarget 2017, 8 , 23927-23936. [CrossRef]

190. Wang, X.; Han, L.; Zhou, L.; Wang, L.; Zhang, L.M. Prediction of candidate RNA signatures for recurrent ovarian cancer prognosis by the construction of an integrated competing endogenous RNA network. Oncol. Rep. 2018, 40, 2659-2673. [CrossRef]

191. Lorenzi, L.; Avila Cobos, F.; Decock, A.; Everaert, C.; Helsmoortel, H.; Lefever, S.; Verboom, K.; Volders, P.J.; Speleman, F.; Vandesompele, J.; et al. Long noncoding RNA expression profiling in cancer: Challenges and opportunities. Genes Chromosomes Cancer 2019, 58, 191-199. [CrossRef] [PubMed]

192. Venter, J.C.; Adams, M.D.; Myers, E.W.; Li, P.W.; Mural, R.J.; Sutton, G.G.; Smith, H.O.; Yandell, M.; Evans, C.A.; Holt, R.A.; et al. The sequence of the human genome. Science 2001, 291, 1304-1351. [CrossRef] [PubMed]

193. Everaert, C.; Luypaert, M.; Maag, J.L.V.; Cheng, Q.X.; Dinger, M.E.; Hellemans, J.; Mestdagh, P. Benchmarking of RNA-sequencing analysis workflows using whole-transcriptome rt-qpcr expression data. Sci. Rep. 2017, 7, 1559. [CrossRef] [PubMed]

194. Assefa, A.T.; De Paepe, K.; Everaert, C.; Mestdagh, P.; Thas, O.; Vandesompele, J. Differential gene expression analysis tools exhibit substandard performance for long non-coding RNA-sequencing data. Genome Biol. 2018, 19, 96. [CrossRef]

195. Mercer, T.R.; Gerhardt, D.J.; Dinger, M.E.; Crawford, J.; Trapnell, C.; Jeddeloh, J.A.; Mattick, J.S.; Rinn, J.L. Targeted RNA sequencing reveals the deep complexity of the human transcriptome. Nat. Biotechnol. 2011, 30, 99-104. [CrossRef]

196. Clark, M.B.; Mercer, T.R.; Bussotti, G.; Leonardi, T.; Haynes, K.R.; Crawford, J.; Brunck, M.E.; Cao, K.A.; Thomas, G.P.; Chen, W.Y.; et al. Quantitative gene profiling of long noncoding RNAs with targeted RNA sequencing. Nat. Methods 2015, 12, 339-342. [CrossRef]

197. Wong, B.C.; Chiu, R.W.; Tsui, N.B.; Chan, K.C.; Chan, L.W.; Lau, T.K.; Leung, T.N.; Lo, Y.M. Circulating placental RNA in maternal plasma is associated with a preponderance of 5' mRNA fragments: Implications for noninvasive prenatal diagnosis and monitoring. Clin. Chem. 2005, 51, 1786-1795. [CrossRef]

198. Luo, J.; Xiong, Y.; Fu, P.F.; Li, E.C.; Qu, L.; Fan, X.; Cai, Z.J.; Lin, A.F. Exosomal long non-coding RNAs: Biological properties and therapeutic potential in cancer treatment. J. Zhejiang Univ. Sci. B 2019, 20, 488-495. [CrossRef]

199. Mohankumar, S.; Patel, T. Extracellular vesicle long noncoding RNA as potential biomarkers of liver cancer. Brief. Funct. Genom. 2016, 15, 249-256. [CrossRef] [PubMed]

200. Zhao, R.; Zhang, Y.; Zhang, X.; Yang, Y.; Zheng, X.; Li, X.; Liu, Y.; Zhang, Y. Exosomal long noncoding RNA hottip as potential novel diagnostic and prognostic biomarker test for gastric cancer. Mol. Cancer 2018, 17, 68. [CrossRef]

201. Li, X.; Corbett, A.L.; Taatizadeh, E.; Tasnim, N.; Little, J.P.; Garnis, C.; Daugaard, M.; Guns, E.; Hoorfar, M.; Li, I.T.S. Challenges and opportunities in exosome research-perspectives from biology, engineering, and cancer therapy. APL Bioeng. 2019, 3, 011503. [CrossRef] [PubMed]

202. Goudarzi, M.; Berg, K.; Pieper, L.M.; Schier, A.F. Individual long non-coding RNAs have no overt functions in zebrafish embryogenesis, viability and fertility. eLife 2019, 8. [CrossRef] [PubMed] 
203. Zhao, Y.; Teng, H.; Yao, F.; Yap, S.; Sun, Y.; Ma, L. Challenges and strategies in ascribing functions to long noncoding RNAs. Cancers 2020, 12, 1458. [CrossRef]

204. Derrien, T.; Johnson, R.; Bussotti, G.; Tanzer, A.; Djebali, S.; Tilgner, H.; Guernec, G.; Martin, D.; Merkel, A.; Knowles, D.G.; et al. The gencode v7 catalog of human long noncoding RNAs: Analysis of their gene structure, evolution, and expression. Genome Res. 2012, 22, 1775-1789. [CrossRef] [PubMed]

205. Washietl, S.; Kellis, M.; Garber, M. Evolutionary dynamics and tissue specificity of human long noncoding RNAs in six mammals. Genome Res. 2014, 24, 616-628. [CrossRef]

206. Bajan, S.; Hutvagner, G. RNA-based therapeutics: From antisense oligonucleotides to miRNAs. Cells 2020, 9, 137. [CrossRef]

207. Landen, C.N., Jr.; Chavez-Reyes, A.; Bucana, C.; Schmandt, R.; Deavers, M.T.; Lopez-Berestein, G.; Sood, A.K. Therapeutic epha2 gene targeting in vivo using neutral liposomal small interfering RNA delivery. Cancer Res. 2005, 65, 6910-6918. [CrossRef]

208. Hanna, N.; Ohana, P.; Konikoff, F.M.; Leichtmann, G.; Hubert, A.; Appelbaum, L.; Kopelman, Y.; Czerniak, A.; Hochberg, A. Phase 1/2a, dose-escalation, safety, pharmacokinetic and preliminary efficacy study of intratumoral administration of bc-819 in patients with unresectable pancreatic cancer. Cancer Gene Ther. 2012, 19, 374-381. [CrossRef]

209. Lavie, O.; Edelman, D.; Levy, T.; Fishman, A.; Hubert, A.; Segev, Y.; Raveh, E.; Gilon, M.; Hochberg, A. A phase $1 / 2 \mathrm{a}$, dose-escalation, safety, pharmacokinetic, and preliminary efficacy study of intraperitoneal administration of bc-819 (h19-dta) in subjects with recurrent ovarian/peritoneal cancer. Arch. Gynecol. Obstet. 2017, 295, 751-761. [CrossRef]

(C) 2020 by the authors. Licensee MDPI, Basel, Switzerland. This article is an open access article distributed under the terms and conditions of the Creative Commons Attribution (CC BY) license (http://creativecommons.org/licenses/by/4.0/). 